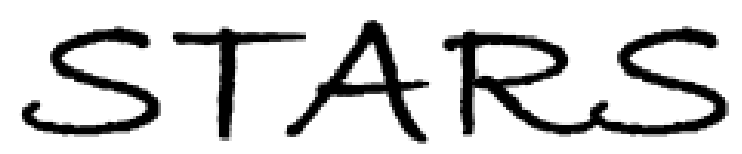

University of Central Florida

STARS

\title{
A Joint Econometric Approach for Modeling Crash Counts by Collision Type
}

Tanmoy Bhowmik

University of Central Florida

Part of the Civil Engineering Commons, and the Transportation Engineering Commons

Find similar works at: https://stars.library.ucf.edu/etd

University of Central Florida Libraries http://library.ucf.edu

This Masters Thesis (Open Access) is brought to you for free and open access by STARS. It has been accepted for inclusion in Electronic Theses and Dissertations by an authorized administrator of STARS. For more information, please contact STARS@ucf.edu.

\section{STARS Citation}

Bhowmik, Tanmoy, "A Joint Econometric Approach for Modeling Crash Counts by Collision Type" (2018). Electronic Theses and Dissertations. 6211.

https://stars.library.ucf.edu/etd/6211

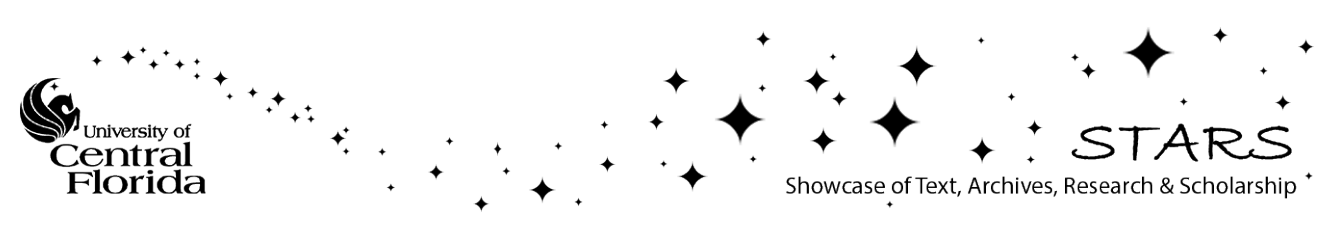




\section{A JOINT ECONOMETRIC APPROACH FOR MODELING CRASH COUNTS BY COLLISION TYPE}

by

TANMOY BHOWMIK

B.Sc. Bangladesh University of Engineering and Technology, 2014

A thesis submitted in partial fulfillment of the requirements for the degree of Master of Science

in the Department of Civil, Environmental and Construction Engineering in the College of Engineering and Computer Science at the University of Central Florida

Orlando, Florida

Spring Term

2018

Major Professor: Naveen Eluru 
(C) 2018 Tanmoy Bhowmik 


\begin{abstract}
In recent years, there is growing recognition that common unobserved factors that influence crash frequency by one attribute level are also likely to influence crash frequency by other attribute levels. The most common approach employed to address the potential unobserved heterogeneity in safety literature is the development of multivariate crash frequency models. The current study proposes an alternative joint econometric framework to accommodate for the presence of unobserved heterogeneity - referred to as joint negative binomial-multinomial logit fractional split (NB-MNLFS) model. Furthermore, the study undertakes a first of its kind comparison exercise between the most commonly used multivariate model (multivariate random parameter negative binomial model) and the proposed joint approach by generating an equivalent log-likelihood measure. The empirical analysis is based on the zonal level crash count data for different collision types from the state of Florida for the year 2015. The model results highlight the presence of common unobserved effects affecting the two components of the joint model as well as the presence of parameter heterogeneity. The equivalent log-likelihood and goodness of fit measures clearly highlight the superiority of the proposed joint model over the commonly used multivariate approach.
\end{abstract}




\section{ACKNOWLEDGMENT}

I would like to convey my heartiest gratitude to my honorable supervisor Dr. Naveen Eluru for his excellent supervision and being a constant support in this thesis.

I would also like to gratefully acknowledge Signal Four Analytics (S4A) and Florida Department of Transportation (FDOT) for providing access to Florida crash and geospatial data.

I would like to convey my heartiest gratitude to Dr. Shamsunnahar Yasmin who helped me a lot throughout the journey in University of Central Florida and guide me through the thesis. 


\section{TABLE OF CONTENT}

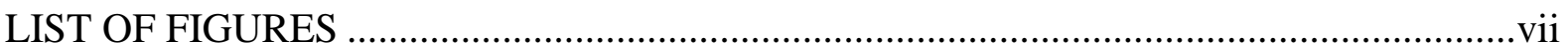

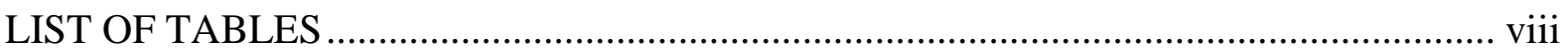

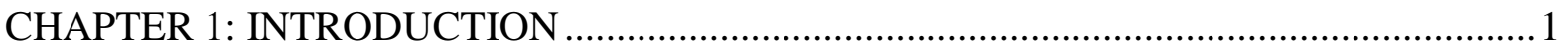

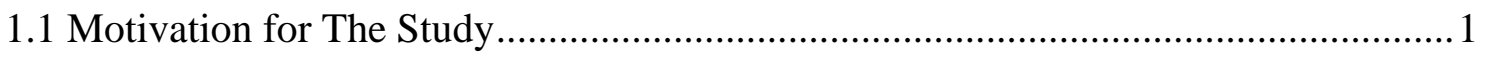

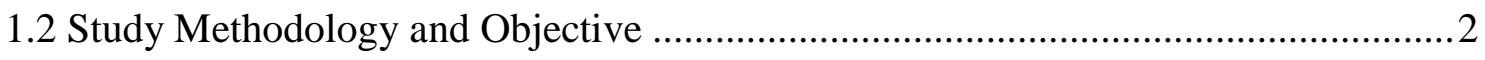

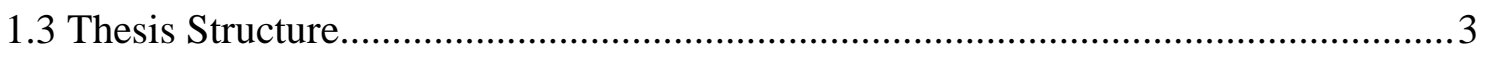

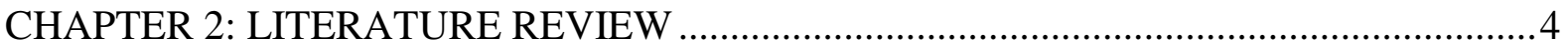

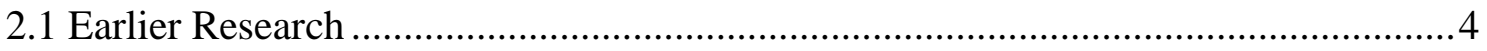

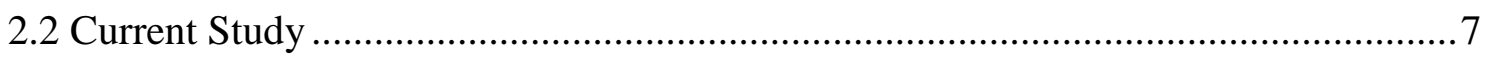

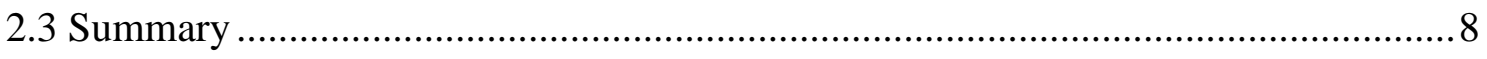

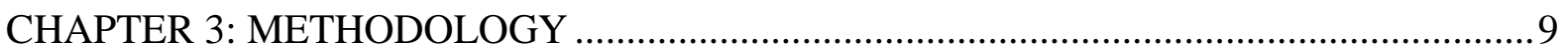

3.1 Negative Binomial (NB) Model Structure ...................................................... 9

3.2 Multivariate Random Parameter Negative Binomial Model .................................. 10

3.3 Joint NB-MNL Fractional Split Model (NB-MNLFS) ....................................... 12

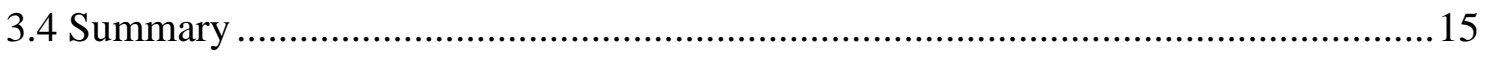

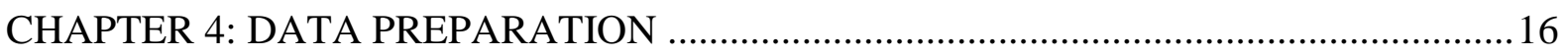

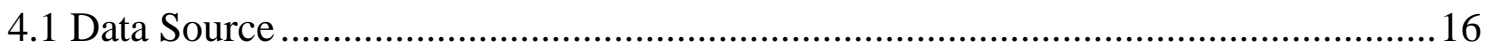

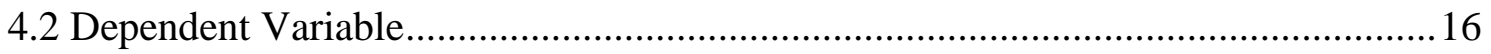

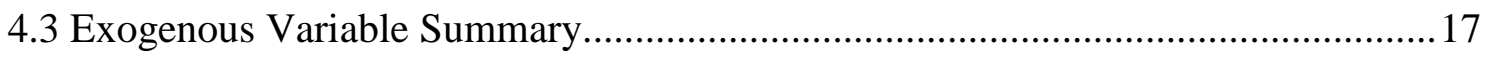

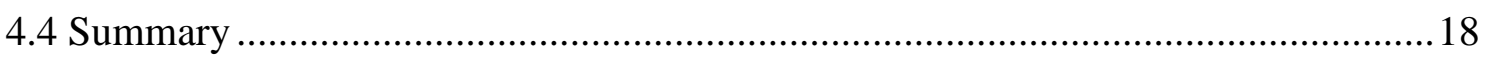

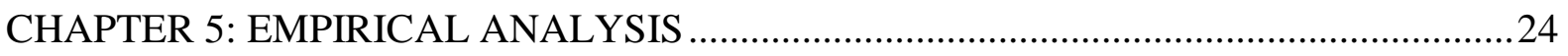

5.1 Model Specification and Overall Measure of Fit ...................................................24

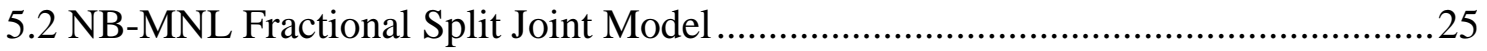


5.2.1 NB Component (Total Crash) ...........................................................25

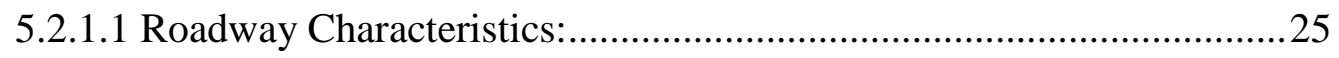

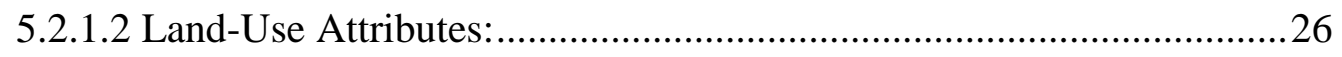

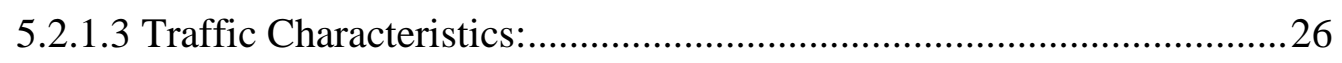

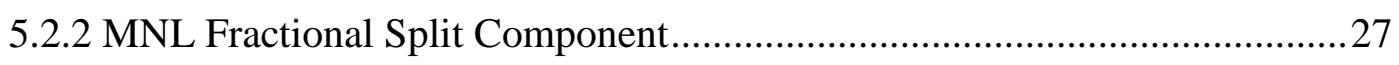

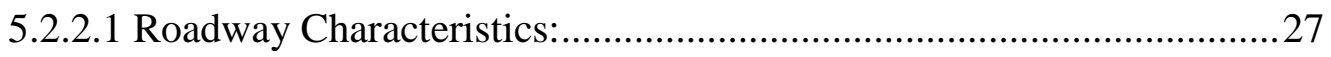

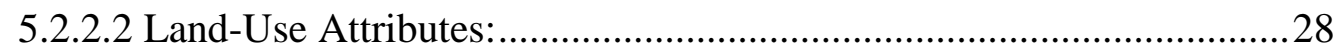

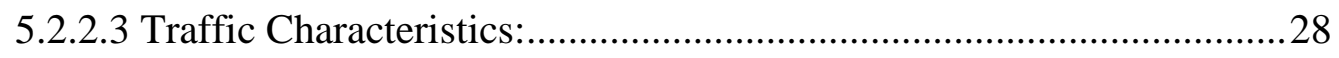

5.2.3 Common Unobserved Effects .............................................................2 28

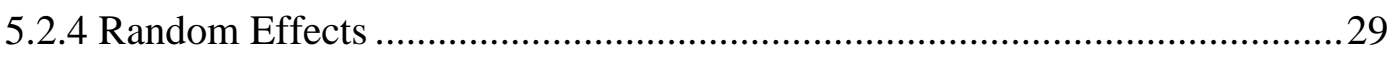

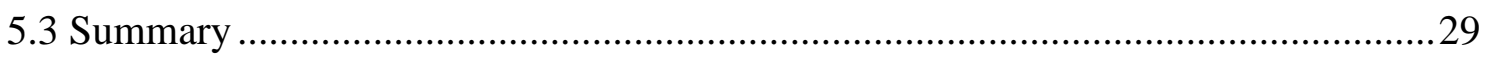

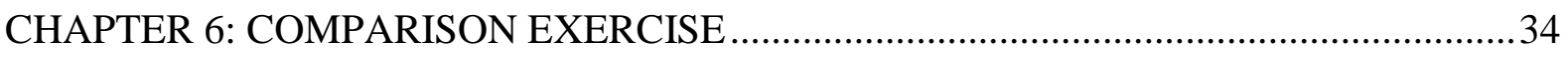

6.1 Equivalent Log-Likelihood Measure ............................................................. 34

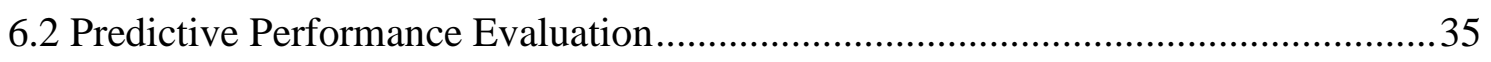

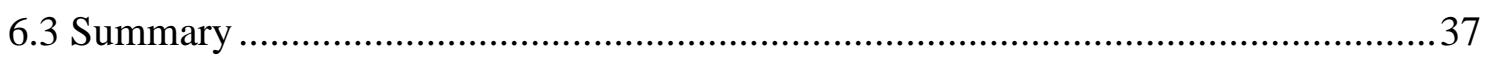

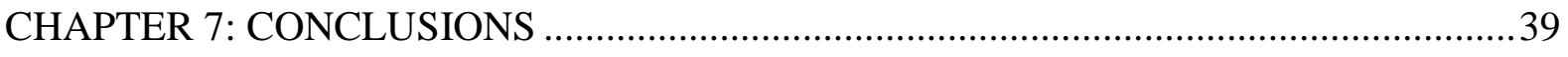

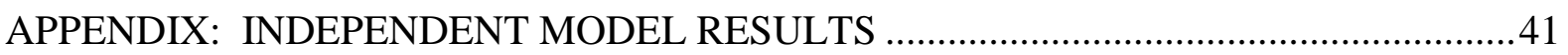

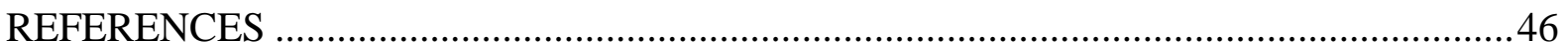




\section{LIST OF FIGURES}

Figure 4.1 Crash (\%) Picture in Florida in 2015 for Different Collision Types ...................... 17 


\section{LIST OF TABLES}

Table 4.1 Descriptive Statistics of Dependent Variables.................................................. 19

Table 4.2 Summary Statistics of Exogenous Variables .................................................... 21

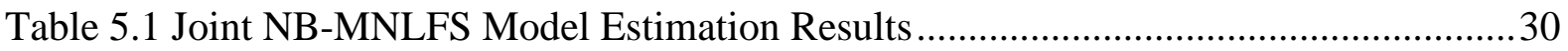

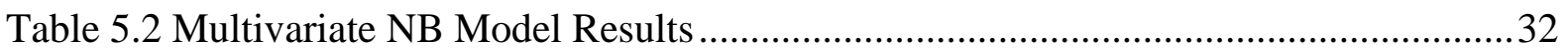

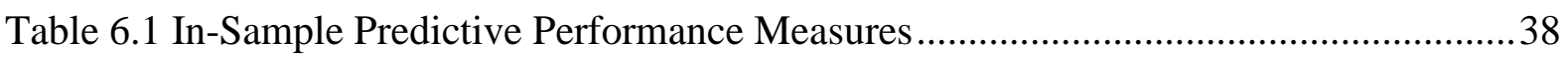

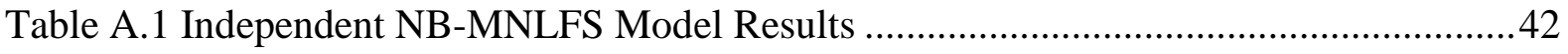

Table A.2 Independent Multivariate NB Model Results .......................................................44 


\section{CHAPTER 1: INTRODUCTION}

Road traffic crashes are responsible for nearly 1.25 million fatalities every year and are a leading cause of death among people aged between 15 and 29 years old (World Health Organization, 2015). The extent of societal, emotional and economic impacts of these unfortunate events has warranted coordinated multi-sectoral responses from the fields of transportation, public health, and medicine. A major analytical tool employed for examining the critical factors influencing crash occurrence include the econometric crash prediction/ frequency models. These models examine crashes at the micro-level (such as an intersection or roadway segment) or at the macro-level (such as a county or Traffic Analysis Zone (TAZ)). The various crash frequency dimensions frequently explored in existing literature include total crashes, crashes by severity, crashes by collision type and crashes by vehicle type for a spatial unit over a given time period.

\subsection{Motivation for The Study}

A majority of the existing studies in safety literature developed crash frequency models for a single dependent variable; the methods are referred to as univariate modeling approaches (see Lord and Mannering, 2010; Yasmin and Eluru, 2017 for a detailed review of these studies). In recent years, there is growing recognition that univariate approaches, while adequate for analyzing a single dependent variable, fall short in modeling multiple crash frequency variables for a single observational unit. For example, the total number of crashes in a TAZ are a sum of crashes by different collision types (or severity levels) i.e. as opposed to analyzing a single total crash variable it is possible to examine crash frequency by different attribute categories. In this case, an extension of univariate approach would be to develop multiple univariate models with frequency by attribute levels considered as multiple dependent variables. Through 
this approach, the exogenous variables affecting crash counts can exhibit distinct impacts on different attribute levels allowing for a flexible specification. The separate models for crash frequency by attribute level allows us to capture realistic estimates of exogenous variables. Yet, the approach only accommodates for observed factors and inherently neglects the information that the multiple crash frequency variables for a TAZ are potentially correlated. For example, for zonal level crash frequency analysis, it is possible that several characteristics specific to the zone such as driver behavior, geometric design and build quality (possibly of higher or lower quality relative to the other zones) and traffic signal design objectives might influence different crash counts by collision type (such as head-on, rear-end). These factors that influence crash frequency by one attribute level are also likely to influence crash frequency by other attribute levels. Such detailed characteristics are rarely available to analysts for consideration in model development. Ignoring for the presence of such unobserved heterogeneity in model development will result in inaccurate and biased model estimates (see Mannering et al., 2016 for an extensive discussion).

\subsection{Study Methodology and Objective}

The most common approach employed to address the potential unobserved heterogeneity in safety literature is the development of multivariate crash frequency models. In this approach, the impact of exogenous variables is quantified through the propensity component of count models. The main interaction across different count variables is sought through unobserved effects i.e. there is no interaction of observed effects across the multiple count models. These approaches, in general, partition the error components of the dependent variables to accommodate for a common term and an independent term across dependent variables (see Mannering et al., 2016 for a detailed discussion of various methodologies). In our current study, we develop an alternative approach to accommodate for the presence of 
observed and unobserved heterogeneity. The approach employs a joint crash frequency and multinomial fractional split model to provide an alternative to the multivariate count models in extant literature. The approach builds on recent work by Yasmin and colleagues in multiple studies (Lee et al., 2018; Yasmin et al., 2016; Yasmin and Eluru, 2017). Furthermore, the current study undertakes a first of its kind comparison exercise between the most commonly used multivariate count model (multivariate random parameter negative binomial model) and the proposed approach of the current study. The reader would note that the log-likelihood functions across these models are not directly comparable. Hence, to facilitate a comparison, an equivalent log-likelihood measure is also generated for the proposed joint crash frequency and fractional split model. Finally, an in-sample prediction exercise comparing the two systems is conducted. The models are estimated by using data from Florida at the Statewide Traffic Analysis Zone (STAZ) level for the year 2015.

\subsection{Thesis Structure}

The rest of the thesis is organized as follows: Chapter 2 provides a brief review of relevant earlier research and positions the current study in terms of existing crash type modelling approaches. Chapter 3 describes the formulation of the proposed joint econometric model and random parameter multivariate negative binomial model framework (RPMNB). Chapter 4 discusses a detailed summary of the data source and exogenous variables considered for the analysis. Model estimation results for the proposed joint model and RPMNB model are reported in Chapter 5. A comparison exercise of the two systems is described in Chapter 6. Finally, a summary of model findings and conclusions are presented in Chapter 7. 


\section{CHAPTER 2: LITERATURE REVIEW}

The field of crash modeling is vast. Several research efforts have been conducted throughout the years for developing crash prediction models by different attributes such as mode, crash type, crash severity etc. Based on the dimensions of the dependent variable considered, these studies can be broadly classified into three categories:

1. Univariate Count Model: A single count variable is examined for an observation (such as a spatial unit or roadway segment.

2. Multivariate Count Model: Multiple dependent variables are jointly analyzed for a spatial unit or a roadway segment.

3. Crash Proportion Model: Instead of counts, proportion of crash is used as a dependent variable for a spatial unit or roadway segment.

In this chapter, we present a detailed discussion of the various model structures used in existing literature and position our current study in context.

\subsection{Earlier Research}

Earlier research efforts in safety literature have focused on univariate model systems for crash frequency analysis. Majority of these studies focus on crash frequency by vehicle involvement (Ivan et al., 2000; Persaud and Mucsi, 1995; Qin et al., 2004; Zhou and Sisiopiku, 1997) or crash type (Chai and Wong, 2014; Li et al., 2016; Wang and Abdel-Aty, 2008a, 2008b, 2006; Yan et al., 2005). It is beyond the scope of our paper to review the vast literature of univariate models (please see Lord and Mannering, 2010; Yasmin and Eluru, 2017 for a literature review).

Recently, research in safety literature has shifted toward modeling multiple dependent variables for each observation unit. The most common approach for modeling multiple 
dependent variables such as crash frequency by severity or collision type is based on using a multivariate crash frequency model. In these models, every crash frequency variable is associated with its corresponding propensity equation (similar to univariate system). Thus, we allow for the impact of exogenous variables to vary across crash frequency variables. For example, consider the exogenous variable - presence of left guardrail on the roadway. In the presence of a left guardrail, vehicles are prevented from entering the opposite direction thus reducing head-on crashes. On the other hand, vehicles on hitting the guardrail might collide with other vehicles travelling in the same direction. Thus, the overall impact of the guardrail might be an increase in total crashes with distinct effects on head-on and sideswipe crashes. So, considering the guardrail variable in the total crash would yield a positive sign. However, considering the same variable in separate univariate models for head-on collisions and sideswipe collisions offer different results. This is an example of how observed variables exhibit contrasting effects on crash occurrence by collision ${ }^{1}$ type. Thus, developing separate models for frequency by collision type allows us to capture realistic estimates of exogenous variables.

In addition to observed factors, the multivariate models inherently account for correlation across multiple crash frequency variables for an observation unit. Ignoring for the presence of such unobserved heterogeneity (associated with missing information or inherently unobservable phenomenon affecting crashes) in model development will result in inaccurate and biased model estimates (see Mannering et al., 2016 for an extensive discussion). In these multivariate models, typically probability computation requires integrating the probability function over the error term distribution. The exact computation is dependent on the

\footnotetext{
${ }^{1}$ We use crash and collision synonymously in the current study context.
} 
distributional assumption and does not have a closed form expression usually ${ }^{2}$. Several studies recognizing the importance of unobserved heterogeneity have developed multivariate approaches that account for the potential dependency across count variables. The various model structures developed from multivariate models include multivariate Poisson regression model (Ye et al., 2009), multivariate Poisson lognormal model (Serhiyenko et al., 2016), multinomialgeneralized Poisson model (Chiou and Fu, 2013), multivariate Poisson gamma mixture count model (Mothafer et al., 2016), multivariate Poisson lognormal spatial and temporal model (Aguero-Valverde et al., 2016; Cheng et al., 2017), Integrated Nested Laplace Approximation Multivariate Poisson Lognormal model (Wang et al., 2017), Bayesian latent class flexible mixture multivariate model (Heydari et al., 2017) and multivariate random-parameters zeroinflated negative binomial model (Anastasopoulos, 2016).

An alternative approach - referred to as the fractional split approach - for modeling crash frequency by attribute level is recently being applied in safety literature (Eluru et al., 2013; Papke and Wooldridge, 1996). In a fractional split approach, as opposed to modeling the count events, count proportions by different attributes (such as injury severity, collision type or vehicle type) for a study unit are examined. The fractional split approach directly relates a single exogenous variable to count proportions of all attribute levels simultaneously. Thus, in this model, exogenous variables affect attribute proportions allowing us to obtain a parsimonious specification. This is in contrast to the multivariate crash models where the observed variables in count propensity equations do not interact with other count variables in the model system.

\footnotetext{
${ }^{2}$ In some cases, a parametric multivariate distributional assumption might result in closed form approaches such as the copula based approach (Nashad et al., 2016).
} 
In safety literature, very few studies have employed the fractional split approach. Milton et al. (2008) developed a mixed multinomial fractional split model to study injuryseverity distribution of crashes on highway segments by using highway-injury data from Washington State. A number of studies have also examined crash frequency by severity simultaneously by building on multinomial-Poisson transformation (Chiou et al., 2014; Chiou and $\mathrm{Fu}, 2015,2013$ ). Geedipally et al. (2010) developed independent crash count (negative binomial model) and crash proportion model (multinomial fractional split) to investigate whether the model system can be used for the estimation of crash counts for each collision type. The study concluded that their approach offered good results. However, the study ignored the influence of common unobserved factors between the crash model and the proportion model. Yasmin et al. (2016) developed an ordered outcome fractional split model that allows the analysis of proportion for variables with multiple alternatives. The approach is applicable only for crash proportions that are ordered. A particularly relevant research effort, Yasmin and Eluru, (2017) extended the ordered proportional framework to incorporate crash frequency (as a negative binomial model) along with crash proportion by injury severity (as an ordered fractional split model).

\subsection{Current Study}

The literature review clearly highlights the prevalence of multivariate model frameworks in safety literature. An alternative approach - fractional split model is emerging as a promising alternative framework for multivariate counts. However, so far there has not been a comprehensive comparison exercise between these two systems. In this context, the current study makes three methodological contributions.

First, we develop the first joint system for total crash counts and multinomial fractional split model. Specifically, we propose to estimate a joint negative binomial-multinomial logit 
fractional split (NB-MNLFS) model. The work builds on Yasmin and colleagues' recent work in the ordered and unordered fractional split realm. Within the joint framework, we also accommodate for random parameters in the count and fractional split components.

Second, the data fit measures of multivariate count model and the proposed joint system are not directly comparable because of the differences in estimation techniques for the two approaches. In the current study, we propose an equivalent log-likelihood measure for the proposed joint NB-MNLFS system to evaluate comparable data fit metrics.

Third, we undertake a comprehensive comparison exercise between the most commonly employed multivariate model and its fractional counterpart. Specifically, we examine performance in model estimation and prediction for multivariate negative binomial model that accommodates unobserved heterogeneity and the proposed joint model.

Empirically, the study develops crash frequency by collision type. The models are estimated using STAZ level crash data for the year 2015 for the state of Florida. The model results offer insights on important variables affecting crash frequency, as well as crash proportion by collision type.

\subsection{Summary}

This chapter presented a detailed summary of methodologies employed in earlier studies for predicting crashes for different spatial unit for different attribute levels. Further, the chapter positioned the current research work in context. The econometric framework employed in this study is described in detail in the subsequent chapter. 


\section{CHAPTER 3: METHODOLOGY}

The previous chapter presented a detailed discussion of the different modeling frameworks used in earlier research for crash type modelling. In this section, we provide details of the model frameworks employed in our study. The chapter starts with the formulation for the traditional negative binomial model and provides details of the advanced modeling structures subsequently.

\subsection{Negative Binomial (NB) Model Structure}

Let us assume that $i(i=1,2,3, \ldots, N)$ be the index for STAZ. Let $l$ be the index representing different crash count level, where $j\left(j=1,2,3, \ldots, J ; j \in K\right.$ and $\left.K=\sum_{j=1}^{J} j\right)$ be the index to represent different collision types and $K$ represents total crashes at a zonal level. In this empirical study, the index $j$ may take the values of rear-end $(j=1)$, head-on $(j=2)$, angular $(J=3)$, off-road $(j=4)$, other single vehicle $(j=5)$, other multiple vehicles $(j=6)$, rollover $(j=7)$ and sideswipe $(j=8)$ crashes. Using these notations, the equation system for modeling crash count across different crash count level $l$, $(l$ can denote either total crashes or crash counts by different collision types) in the usual NB formulation can be written as:

$$
P\left(c_{i l}\right)=\frac{\Gamma\left(c_{i l}+\frac{1}{\alpha_{l}}\right)}{\Gamma\left(c_{i l}+1\right) \Gamma\left(\frac{1}{\alpha_{l}}\right)}\left(\frac{1}{1+\alpha_{l} \mu_{i l}}\right)^{\frac{1}{\alpha_{l}}}\left(1-\frac{1}{1+\alpha \mu_{i l}}\right)^{c_{i l}}
$$

where, $c_{i l}$ be the index for crash counts specific to level $l$ occurring over a period of time in STAZ $i . P\left(c_{i l}\right)$ is the probability that STAZ $i$ has $c_{i l}$ number of crashes for crash count level $l . \Gamma(\cdot)$ is the gamma function, $\alpha_{l}$ is NB over dispersion parameter and $\mu_{i l}$ is the expected number of crashes occurring in STAZ $i$ over a given time period for crash count level $l$. 


\subsection{Multivariate Random Parameter Negative Binomial Model}

The focus of multivariate NB model is to examine number of crashes across different collision types jointly. In our current study context, we consider eight different collision types (rear-end, head-on, angular, off-road, others single vehicle, others multiple vehicles, rollover and sideswipe crashes). Thus, in estimating multivariate NB model, we examine eight different NB models for eight different collision types simultaneously. For the multivariate approach, the equation system for modeling crash count across different collision types can be written by replacing the subscript $l$ with $j$ in equation 1 . Thus, the probability for crash occurrence for different crash type $j$ can be represented as $P\left(c_{i j}\right)$, for which we can express $\mu_{i j}$ as a function of explanatory variables by using a log-link function as follows:

$$
\mu_{i j}=E\left(c_{i j} \mid \mathbf{z}_{i j}\right)=\exp \left(\left(\boldsymbol{\delta}_{j}+\boldsymbol{\zeta}_{i j}\right) \mathbf{z}_{i j}+\ln \left(\text { Area }_{i}\right)+\varepsilon_{i j}+\eta_{i j}\right)
$$

where, $\boldsymbol{z}_{i j}$ is a vector of explanatory variables associated with STAZ $i$ and collision type $j$. Area $_{i}$ is the STAZ area used as an offset variable in the NB model specification ${ }^{3} . \boldsymbol{\delta}_{j}$ is a vector of coefficients to be estimated. $\zeta_{i j}$ is a vector of unobserved factors on crash count propensity associated with collision type $j$ for STAZ $i$ and its associated zonal characteristics, assumed to be a realization from standard normal distribution: $\zeta_{i j} \sim N\left(0, \pi_{j}^{2}\right) . \varepsilon_{i j}$ is a gamma distributed error term with mean 1 and variance $\alpha_{j} . \eta_{i j}$ captures unobserved factors that simultaneously impact number of crashes across different collision types for STAZ $i$. Here, it

\footnotetext{
${ }^{3}$ STAZ areas under consideration vary from $10^{-7}$ mile $^{2}$ to 885.321 mile ${ }^{2}$ with a mean of 6.472 mile ${ }^{2}$
} Given the wide range in STAZ areas, we allow the area associated with STAZs as an offset variable to account for different sizes of STAZs in our model specification. The coefficient of the offset variable is restricted to be one in estimating the model to normalize for the number crash events by STAZ area. 
is important to note that the unobserved heterogeneity between total number of crashes across different collision types can vary across STAZs. Therefore, in the current study, the correlation parameter $\eta_{i}$ is parameterized as a function of observed attributes as follows:

$$
\eta_{i j}=\gamma_{j} s_{i j}
$$

where, $\boldsymbol{s}_{i j}$ is a vector of exogenous variables, $\boldsymbol{\gamma}_{\boldsymbol{j}}$ is a vector of unknown parameters to be estimated (including a constant).

In examining the model structure of crash count across different collision types, it is necessary to specify the structure for the unobserved vectors $\zeta$ and $\boldsymbol{\gamma}$ represented by $\boldsymbol{\Omega}$. In this paper, it is assumed that these elements are drawn from independent normal distributions: $\Omega \sim N\left(0,\left(\boldsymbol{\pi}_{j}{ }^{2}, \boldsymbol{\sigma}_{j}^{2}\right)\right)$. Thus, conditional on $\boldsymbol{\Omega}$, the likelihood function for the joint probability can be expressed as:

$$
L_{i}=\int_{\mathbf{\Omega}} \prod_{j=1}^{J}\left(P\left(c_{i j}\right)\right) f(\boldsymbol{\Omega}) d \mathbf{\Omega}
$$

Finally, the log-likelihood function is:

$$
L L=\sum_{i} \operatorname{Ln}\left(L_{i}\right)
$$

All the parameters in the model are estimated by maximizing the logarithmic function $L L$ presented in equation 5 . The parameters to be estimated in the multivariate NB model are: $\boldsymbol{\delta}_{j}, \alpha_{j}, \boldsymbol{\pi}_{j}$, and $\boldsymbol{\sigma}_{\boldsymbol{j}}$. 


\subsection{Joint NB-MNL Fractional Split Model (NB-MNLFS)}

The focus of joint NB-MNL fractional split model is to jointly model "total number of crashes" and "proportion of crashes by crash types". Thus, we examine one NB model for total crash count and one MNL fractional split model for crash proportion by crash types simultaneously. For the joint approach, the equation system for modeling total crash count in the usual NB formulation can be written by replacing subscript $l$ by $K$ in equation 1 . Thus, the probability for crash occurrence for total crash count $K$ can be represented as $P\left(c_{i K}\right)$, for which we can express $\mu_{i K}$ as a function of explanatory variables by using a log-link function as follows:

$$
\mu_{i K}=E\left(c_{i K} \mid \boldsymbol{x}_{i}\right)=\exp \left(\left(\boldsymbol{\theta}+\varrho_{i}\right) \boldsymbol{x}_{i}+\ln \left(\text { Area }_{i}\right)+\phi_{i}+\psi_{i j}\right)
$$

where, $\boldsymbol{x}_{i}$ is a vector of explanatory variables associated with STAZ $i$. Area $a_{i}$ is the STAZ area used as an offset variable in the NB model specification. $\boldsymbol{\theta}$ is a vector of coefficients to be estimated. $\varrho_{i}$ is a vector of unobserved factors on crash count propensity for STAZ $i$ and its associated zonal characteristics assumed to be a realization from standard normal distribution: $\varrho_{i} \sim N\left(0, \varsigma^{2}\right) . \phi_{i}$ is a gamma distributed error term with mean 1 and variance $\alpha_{K}$. $\psi_{i j}$ captures unobserved factors that simultaneously impact total number of crashes and proportion of crashes by crash types for STAZ $i$.

In the joint model framework, the modeling of crash proportions by crash types is undertaken using the MNL fractional split model. In our current study, the dependent variable in the crash proportion component of the joint model is defined as the proportion of crash type in traffic crashes by STAZ. In estimating the model, we assume that the sum of the proportions across a STAZ is equal to unity and each proportion of crash types in traffic crashes ranges between zero and one. Let $y_{i j}$ be the fraction of crashes by crash type $j(j=8)$ in STAZ $i$. 


$$
0 \leq y_{i j} \leq 1, \quad \sum_{j=1}^{J} y_{i j}=1
$$

Let the fraction $y_{i j}$ be a function of a vector $d_{i j}$ of relevant explanatory variables associated with attributes of STAZ $i$.

$$
\begin{aligned}
E\left[y_{i j} \mid d_{i j}\right] & =G_{j}(\cdot) \\
& 0<G_{j}(\cdot)<1, \quad \sum_{j=1}^{J} G_{j}(\cdot)=1
\end{aligned}
$$

where $G_{j}(\cdot)$ is a predetermined function. The properties specified in equation 8 for $G_{j}(\cdot$ ) warrant that the predicted fractional crash types will range between 0 and 1, and will add up to 1 for each STAZ. In this study, a MNL functional form for $G_{j}$ in the fractional split model of equation 8 . Then equation 8 is rewritten as:

$$
E\left(y_{i j} \mid d_{i j}\right)=G_{j}(\cdot)=\frac{\exp \left(\left(\boldsymbol{\beta}_{j}+\boldsymbol{\rho}_{i j}\right) d_{i j}+\xi_{i j} \pm \psi_{i j}\right)}{\sum_{j=1}^{J} \exp \left(\left(\boldsymbol{\beta}_{j}+\boldsymbol{\rho}_{i j}\right) d_{i j}+\xi_{i j} \pm \psi_{i j}\right)}, j=1,2,3, \ldots,
$$

where, $\boldsymbol{d}_{i j}$ is a vector of attributes, $\boldsymbol{\beta}_{j}$ is the corresponding vector of coefficients to be estimated for crash type $j . \boldsymbol{\rho}_{i j}$ is a vector of unobserved factors assumed to be a realization from standard normal distribution: $\boldsymbol{\rho} \sim N\left(0, \boldsymbol{v}_{j}{ }^{2}\right) . \xi_{i j}$ is the random component assumed to follow a Gumbel type 1 distribution. $\psi_{i j}$ term generates the correlation between equations for total number of crashes and crash proportions by crash types. The \pm sign in front of $\psi_{i j}$ in equation 9 indicates that the correlation in unobserved zonal factors between total crashes and crash proportions by crash type may be positive or negative. A positive sign implies that STAZs with higher number of crashes are intrinsically more likely to incur higher proportions for the 
corresponding crash types. On the other hand, negative sign implies that STAZs with higher number of crashes intrinsically incur lower proportions for different crash types. To determine the appropriate sign, one can empirically test the models with both ' $+{ }^{\prime}$ and ' $-{ }^{\prime}$ signs independently. The model structure that offers the superior data fit is considered as the final model.

It is important to note here that the unobserved heterogeneity between total number of crashes and crash proportions by crash types can vary across STAZs. Therefore, in the current study, the correlation parameter $\psi_{i j}$ is parameterized as a function of observed attributes as follows:

$$
\psi_{i j}=\boldsymbol{\Theta}_{j} \boldsymbol{t}_{i j}
$$

where, $\boldsymbol{t}_{i}$ is a vector of exogenous variables, $\boldsymbol{\Theta}_{\boldsymbol{j}}$ is a vector of unknown parameters to be estimated (including a constant).

In examining the model structure of total crash count and proportion of crashes by crash types, it is necessary to specify the structure for the unobserved vectors $\boldsymbol{\varsigma}, \boldsymbol{\rho}$ and $\boldsymbol{\Theta}$ represented by $\mho$. In this paper, it is assumed that these elements are drawn from independent realization from normal population: $\mho \sim N\left(0,\left(\boldsymbol{s}^{2}, \boldsymbol{v}_{j}{ }^{2}, \aleph_{j}^{2}\right)\right)$. Thus, conditional on $\mho$, the likelihood function for the joint probability can be expressed as:

$$
\mathcal{L}_{i}=\int_{\mho} P\left(c_{i K}\right) \times \prod_{j=1}^{J}\left(E\left(y_{i j} \mid d_{i j}\right)\right)^{\varpi_{i} y_{i j}} f(\mho) d \Omega
$$


where, $\varpi_{i}$ is a dummy with $\varpi_{i}=1$ if STAZ $i$ has at least one crash over the study period and 0 otherwise. $y_{i j}$ is the proportion of crashes in crash type category $j$. Finally, the log-likelihood function is:

$$
\mathcal{L} \mathcal{L}=\sum_{i} \operatorname{Ln}\left(L_{i}\right)
$$

All the parameters in the model are estimated by maximizing the logarithmic function $\mathcal{L} \mathcal{L}$ presented in equation 12. The parameters to be estimated in the joint model are: $\boldsymbol{\theta}, \alpha_{K}, \boldsymbol{\beta}_{\boldsymbol{j}}, \boldsymbol{v}_{j}$ and $\aleph_{j}$

To estimate the proposed joint and multivariate models, we apply Quasi-Monte Carlo simulation techniques based on the scrambled Halton sequence to approximate this integral in the likelihood function and maximize the logarithm of the resulting simulated likelihood function across individuals (see Bhat, 2001; Eluru et al., 2008; Yasmin and Eluru, 2013 for examples of Quasi-Monte Carlo approaches in literature). The model estimation routine is coded in GAUSS Matrix Programming software (Aptech, 2015)

\subsection{Summary}

The main objective of the study is to develop an alternative approach to the traditional multivariate NB model for modeling different collision types while accommodating for the presence of common unobserved factors across different collision types. This chapter presented a detailed discussion of the econometric approach employed for crash type modeling in this study. 


\section{CHAPTER 4: DATA PREPARATION}

The previous chapter provided a detailed discussion about the modeling framework employed in the current research effort. This chapter presents characteristics of the data employed for analysis including the source of the data, the compilation of dependent and explanatory variables considered in the analysis.

\subsection{Data Source}

The study draws motorized crash record data from the state of Florida for the year 2015 at STAZ level from Florida Department of Transportation (FDOT), Crash Analysis Reporting System (CARS) and Signal Four Analytics (S4A) databases. CAR and S4A are long and short forms of crash reports in the State of Florida, respectively. The Long Form crash report is used to obtain detailed information on major crashes such as accident resulting in injuries or crashes involving felonious activities (such as hit-and-run or driving under influence). Short Form crash reports depict the reports based on all other traffic crashes. Thus, when integrated, a complete representation of road crashes in Florida is generated.

\subsection{Dependent Variable}

The data provides crash information for 8,518 STAZs. The data reports 10 types of collisions: rear-end, head-on, angular, left-turn, right-turn, off-road, rollover, sideswipe, other collision type with one vehicle involved and other collision type with more than one vehicle involved. Based on crash records the angular, left-turn and right-turn collision types are combined as one category; thus 8 collision type categories are considered. Table 4.1 represents the summary statistics of crash type variables. A total of 487,171 motorized crashes were recorded in Florida during 2015. Figure 4.1 describes the overall summary of all crash types in 
the state of Florida for the year 2015 in terms of percentage. Of these crashes, rear-end collisions are the most prevalent while rollover crashes are less frequent with $1.06 \%$ among all other crash types.

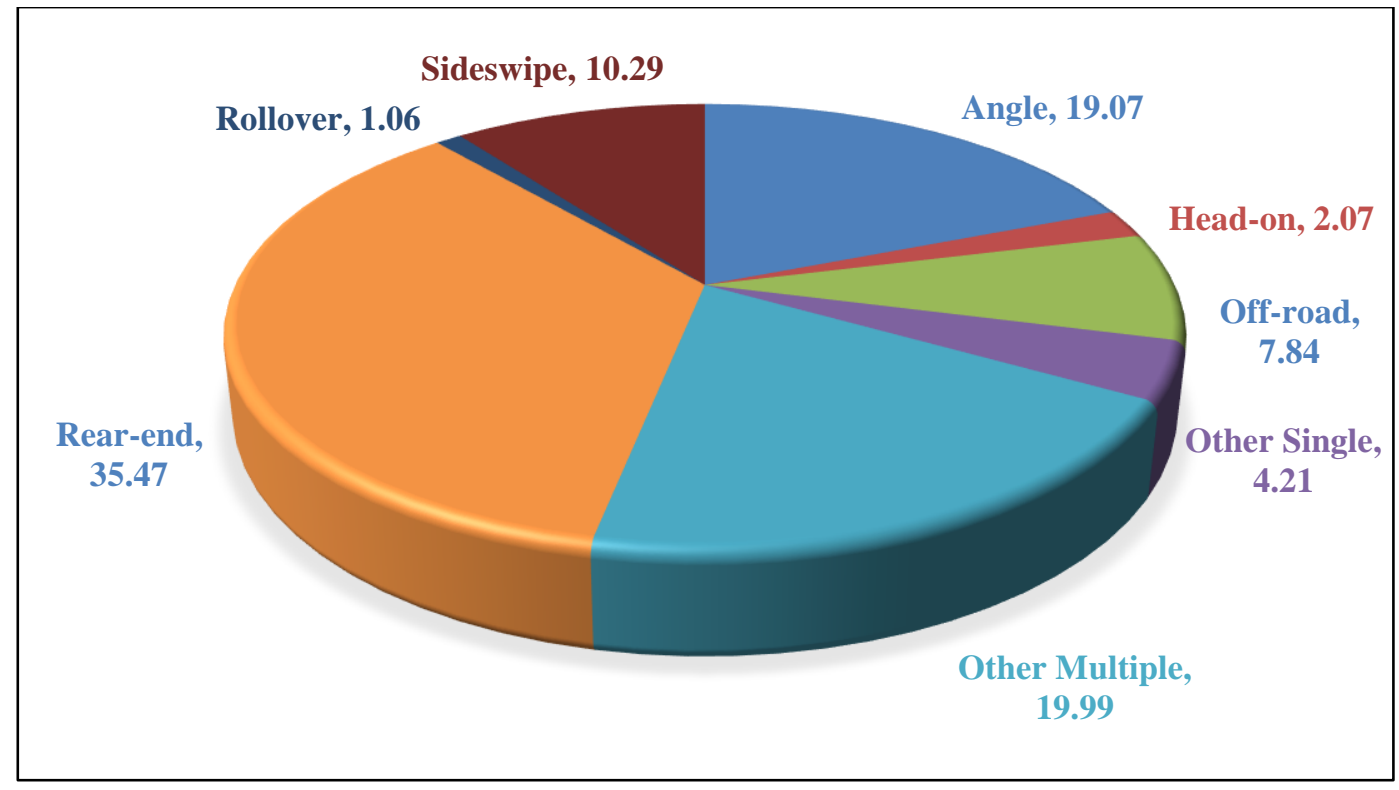

Figure 4.1 Crash (\%) Picture in Florida in 2015 for Different Collision Types

\subsection{Exogenous Variable Summary}

Roadway characteristics, land use attributes and traffic characteristics - three broad categories of explanatory variables are considered in our study. The data employed are obtained from FDOT Transportation Statistics Division, and US Census Bureau. The attributes are then aggregated at a STAZ level using geographical information system (GIS). Roadway attributes included are road lengths for different functional class, access and pavement condition, on road, off-road, divided road and roads with different number of lanes (1, 2 and 3 or more), width and variance of median, intersection and signal density, mean and variance of posted speed limit, average width of the sidewalk, inside and outside shoulder mean width. Intersection density denotes the number of intersection per miles of street in a STAZ and signal density is the number of signals per intersection. Land use attributes included area of urban, residential, 
industrial, institutional, recreational, office, agricultural land use types and land use $\mathrm{mix}^{4}$. Further, for traffic characteristics, average annual daily traffic (AADT), average annual daily truck traffic (truck AADT), vehicles miles traveled (VMT), truck vehicles miles traveled (truck VMT) and proportion of heavy traffic are considered.

All the explanatory variables are created based on previous studies. Table 4.2 summarizes sample characteristics of the explanatory variables with the definition considered for final model estimation along with the zonal minimum, maximum and mean values. Several functional forms and specifications for different variables are explored. The final specification of the model development was based on removing the statistically insignificant variables in a systematic process based on $90 \%$ significance level.

\subsection{Summary}

In this chapter, data compilation procedures are discussed. Further, descriptive statistics for both dependent and independent variables are provided. The empirical analysis results are summarized in the next chapter.

\footnotetext{
${ }^{4}$ Land use mix is defined as: $\left[\frac{-\sum_{k}\left(p_{k}\left(\ln p_{k}\right)\right)}{\ln N}\right]$, where $\mathrm{k}$ is the category of land-use, $p_{k}$ is the proportion of the developed land area devoted to a specific land-use $k, N$ is the number of land-use categories in a STAZ. In our study, six land use types were considered including residential, park facilities, industrial, institutional, agricultural and office areas. Institutional land use refers to land uses that cater to community's social and educational needs (schools, town hall, police station) while park facilities refer to land used for recreational or entertainment purposes. The value of this index ranges from zero to one - zero (no mix) corresponds to a homogenous area characterized by single land use type and one to a perfectly heterogeneous mix).
} 
Table 4.1 Descriptive Statistics of Dependent Variables

\begin{tabular}{|c|c|c|c|c|c|c|}
\hline \multirow[b]{2}{*}{ Variable Names } & \multirow[b]{2}{*}{ Definition } & \multicolumn{5}{|c|}{ Zonal (N=8518) } \\
\hline & & Minimum & Maximum & Average & $\begin{array}{l}\text { Standard } \\
\text { Deviation }\end{array}$ & $\begin{array}{c}\% \text { of STAZs } \\
\text { with zero } \\
\text { crash record }\end{array}$ \\
\hline \multicolumn{7}{|l|}{ Count variables } \\
\hline Total Crash & Total number of crashes in STAZ & 0.000 & 877.000 & 57.193 & 75.999 & 5.100 \\
\hline Rear-end Crash & Total number of rear-end crashes in STAZ & 0.000 & 315.000 & 20.285 & 29.665 & 17.363 \\
\hline Head-on Crash & Total number of head-on crashes in STAZ & 0.000 & 76.000 & 1.185 & 3.382 & 59.779 \\
\hline Angular Crash & Total number of angular crashes in STAZ & 0.000 & 180.000 & 10.907 & 16.623 & 21.930 \\
\hline Off-road Crash & Total number of off-road crashes in STAZ & 0.000 & 65.000 & 4.485 & 5.615 & 21.965 \\
\hline $\begin{array}{l}\text { Other Single Vehicle } \\
\text { Crash }\end{array}$ & Total number of other single vehicle crashes in STAZ & 0.000 & 99.000 & 2.410 & 3.632 & 35.724 \\
\hline $\begin{array}{l}\text { Other Multiple Vehicle } \\
\text { Crash }\end{array}$ & Total number of other multiple vehicle crashes in STAZ & 0.000 & 419.000 & 11.433 & 19.142 & 20.756 \\
\hline Rollover Crash & Total number of rollover crashes in STAZ & 0.000 & 24.000 & 0.605 & 1.286 & 67.739 \\
\hline Sideswipe Crash & Total number of sideswipe crashes in STAZ & 0.000 & 123.000 & 5.883 & 9.091 & 28.575 \\
\hline \multicolumn{7}{|l|}{ Fraction variables } \\
\hline Rear-end crash fraction & $\begin{array}{l}\text { Proportion of rear-end crashes (total number of rear-end } \\
\text { crashes / total number of motorized vehicle crashes in STAZ) }\end{array}$ & 0.000 & 1.000 & 0.284 & 0.198 & 17.363 \\
\hline Head-on crash fraction & $\begin{array}{l}\text { Proportion of head-on crashes (total number of head-on } \\
\text { crashes / total number of motorized vehicle crashes in STAZ) }\end{array}$ & 0.000 & 1.000 & 0.022 & 0.064 & 59.779 \\
\hline Angular crash fraction & $\begin{array}{l}\text { Proportion of angular crashes (total number of angular crashes } \\
\text { / total number of motorized vehicle crashes in STAZ) }\end{array}$ & 0.000 & 1.000 & 0.166 & 0.148 & 21.930 \\
\hline Off-road crash fraction & $\begin{array}{l}\text { Proportion of off-road crashes (total number of off-road } \\
\text { crashes / total number of motorized vehicle crashes in STAZ) }\end{array}$ & 0.000 & 1.000 & 0.132 & 0.179 & 21.965 \\
\hline
\end{tabular}




\begin{tabular}{|c|c|c|c|c|c|c|}
\hline \multirow[b]{2}{*}{ Variable Names } & \multirow[b]{2}{*}{ Definition } & \multicolumn{5}{|c|}{ Zonal $(\mathrm{N}=\mathbf{8 5 1 8})$} \\
\hline & & Minimum & Maximum & Average & $\begin{array}{l}\text { Standard } \\
\text { Deviation }\end{array}$ & $\begin{array}{l}\text { \% of STAZs } \\
\text { with zero } \\
\text { crash record }\end{array}$ \\
\hline $\begin{array}{l}\text { Other single vehicle } \\
\text { crash fraction }\end{array}$ & $\begin{array}{l}\text { Proportion of other single vehicle crashes (total number of } \\
\text { other single vehicle crashes / total number of motorized } \\
\text { vehicle crashes in STAZ) }\end{array}$ & 0.000 & 1.000 & 0.061 & 0.110 & 35.724 \\
\hline $\begin{array}{l}\text { Other multiple vehicle } \\
\text { crash fraction }\end{array}$ & $\begin{array}{l}\text { Proportion of other multiple vehicle crashes (total number of } \\
\text { other multiple vehicle crashes / total number of motorized } \\
\text { vehicle crashes in STAZ) }\end{array}$ & 0.000 & 1.000 & 0.172 & 0.160 & 20.756 \\
\hline Rollover crash fraction & $\begin{array}{l}\text { Proportion of rollover crashes (total number of rollover } \\
\text { crashes / total number of motorized vehicle crashes in STAZ) }\end{array}$ & 0.000 & 1.000 & 0.023 & 0.076 & 67.739 \\
\hline $\begin{array}{l}\text { Sideswipe crash } \\
\text { fraction }\end{array}$ & $\begin{array}{l}\text { Proportion of sideswipe crashes (total number of sideswipe } \\
\text { crashes / total number of motorized vehicle crashes in STAZ) }\end{array}$ & 0.000 & 1.000 & 0.09 & 0.105 & 28.575 \\
\hline
\end{tabular}


Table 4.2 Summary Statistics of Exogenous Variables

\begin{tabular}{|c|c|c|c|c|c|}
\hline \multirow{2}{*}{ Variable Names } & \multirow{2}{*}{ Definition } & \multicolumn{4}{|c|}{ Zonal (N=8518) } \\
\hline & & Minimum & Maximum & Average & $\begin{array}{l}\text { Standard } \\
\text { Deviation } \\
\end{array}$ \\
\hline \multicolumn{6}{|l|}{ Roadway Characteristics } \\
\hline $\begin{array}{l}\text { Proportion of arterial } \\
\text { road }\end{array}$ & Total length of arterial road/ Total road length in STAZ & 0.000 & 1.000 & 0.477 & 0.363 \\
\hline $\begin{array}{l}\text { Proportion of collector } \\
\text { road }\end{array}$ & Total length of collector road/ Total road length in STAZ & 0.000 & 1.000 & 0.410 & $0 . .353$ \\
\hline Proportion of local road & Total length of local road/ Total road length in STAZ & 0.000 & 1.000 & 0.088 & 1.952 \\
\hline Proportion of urban road & Total length of urban road/ Total road length in STAZ & 0.000 & 1.000 & 0.756 & 0.411 \\
\hline Proportion of rural road & Total length of rural road/ Total road length in STAZ & 0.000 & 1.000 & 0.219 & 0.394 \\
\hline $\begin{array}{l}\text { Proportion of no control } \\
\text { road }\end{array}$ & Total length of no access control road/ Total road length in STAZ & 0.000 & 1.000 & 0.912 & 0.245 \\
\hline Proportion of major road & Total length of major road/ Total road length in STAZ & 0.000 & 1.000 & 0.594 & 0.355 \\
\hline Proportion of minor road & Total length of minor road/ Total road length in STAZ & 0.000 & 1.000 & 0.331 & 0.334 \\
\hline Signal intensity & Total number of signal/ Total number of intersection in STAZ & 0.000 & 1.667 & 0.048 & 0.112 \\
\hline Divided road length & Ln (total length of divided road in STAZ in meter) & -1.394 & 12.075 & 6.705 & 3.463 \\
\hline $\begin{array}{l}\text { Proportion of } 1 \text { lane road } \\
\text { length }\end{array}$ & Total length of road with 1 lane / Total road length in STAZ & 0.000 & 1.000 & 0.109 & 0.159 \\
\hline $\begin{array}{l}\text { Proportion of } 2 \text { lane road } \\
\text { length }\end{array}$ & Total length of road with 2 lane / Total road length in STAZ & 0.000 & 1.000 & 0.629 & 0.346 \\
\hline $\begin{array}{l}\text { Proportion of } 3 \text { or more } \\
\text { lane road length }\end{array}$ & $\begin{array}{l}\text { Total length of road with } 3 \text { or more lane / Total road length in } \\
\text { STAZ }\end{array}$ & 0.000 & 1.000 & 0.241 & 0.331 \\
\hline Average median width & Ln (average median width in meter in STAZ) & -0.089 & 5.527 & 1.501 & 0.821 \\
\hline
\end{tabular}




\begin{tabular}{|c|c|c|c|c|c|}
\hline \multirow{2}{*}{ Variable Names } & \multirow{2}{*}{ Definition } & \multicolumn{4}{|c|}{ Zonal (N=8518) } \\
\hline & & Minimum & Maximum & Average & $\begin{array}{l}\text { Standard } \\
\text { Deviation } \\
\end{array}$ \\
\hline Variance of median width & Ln (variance of median width in meter in STAZ) & -4.279 & 11.724 & 1.815 & 2.228 \\
\hline $\begin{array}{l}\text { Average inside shoulder } \\
\text { width }\end{array}$ & Ln (average width of inside shoulder in feet in STAZ) & 0.000 & 2.996 & 0.535 & 0.586 \\
\hline $\begin{array}{l}\text { Average outside shoulder } \\
\text { width }\end{array}$ & Ln (average width of outside shoulder in feet in STAZ) & 0.000 & 3.066 & 1.588 & 0.483 \\
\hline Average sidewalk width & Ln (average width of sidewalk in feet in STAZ) & 0.000 & 3.497 & 1.259 & 0.795 \\
\hline Intersection density & $\begin{array}{l}\text { Ln of total number of intersection per square miles of street in } \\
\text { STAZ (Total number of intersection/ Total length of street in } \\
\text { STAZ in miles) }\end{array}$ & -2.608 & 7.948 & 1.751 & 1.003 \\
\hline $\begin{array}{l}\text { Average posted speed } \\
\text { limit }\end{array}$ & Ln (average posted speed limit in mile per hour in STAZ) & 0.000 & 4.248 & 3.390 & 1.089 \\
\hline $\begin{array}{l}\text { Variance of posted speed } \\
\text { limit }\end{array}$ & Ln (variance of posted speed limit in mile per hour in STAZ) & 0.000 & 6.920 & 2.415 & 1.951 \\
\hline \multicolumn{6}{|l|}{ Built Environment } \\
\hline $\begin{array}{l}\text { Proportion of residential } \\
\text { area }\end{array}$ & Residential area / Total area of STAZ & 0.000 & 0.777 & 0.024 & 0.090 \\
\hline $\begin{array}{l}\text { Proportion of agricultural } \\
\text { area }\end{array}$ & Agricultural area / Total area of STAZ & 0.000 & 0.987 & 0.022 & 0.114 \\
\hline $\begin{array}{l}\text { Proportion of industrial } \\
\text { area }\end{array}$ & Industrial area / Total area of STAZ & 0.000 & 0.871 & 0.002 & 0.022 \\
\hline $\begin{array}{l}\text { Proportion } \\
\text { institutional area }\end{array}$ & Institutional area / Total area of STAZ & 0.000 & 0.585 & 0.019 & 0.134 \\
\hline Proportion of office area & Office and retail area / Total area of STAZ & 0.000 & 0.786 & 0.008 & 0.044 \\
\hline $\begin{array}{l}\text { Proportion of recreational } \\
\text { area }\end{array}$ & Recreational area / Total area of STAZ & 0.000 & 0.965 & 0.004 & 0.037 \\
\hline
\end{tabular}




\begin{tabular}{|c|c|c|c|c|c|}
\hline Land use mix & $\begin{array}{l}\text { Land use mix }=\left[\frac{-\sum_{k}\left(p_{k}\left(\ln p_{k}\right)\right)}{\ln N}\right] \text {, where } k \text { is the category of land- } \\
\text { use, } p \text { is the proportion of the developed land area devoted to a } \\
\text { specific land-use, } N \text { is the number of land-use categories in } \\
\text { STAZ }\end{array}$ & 0.000 & 0.859 & 0.046 & 0.145 \\
\hline Proportion of urban area & Urban area / Total area of STAZ & 0.000 & 1.000 & 0.731 & 0.425 \\
\hline LTZM & $\begin{array}{l}\text { Ln of area of STAZ in meter square (used as the exposure variable } \\
\text { in the model) }\end{array}$ & -3.749 & 21.553 & 14.596 & 2.271 \\
\hline \multicolumn{6}{|l|}{ Traffic Characteristics } \\
\hline AADT & Ln of average annual daily traffic in STAZ & 0.000 & 13.312 & 10.362 & 2.093 \\
\hline Truck AADT & Ln of average annual daily truck traffic in STAZ & 0.000 & 11.020 & 4.901 & 3.870 \\
\hline VMT & Ln of vehicles miles traveled in STAZ & 0.000 & 13.524 & 9.442 & 2.192 \\
\hline Truck VMT & Ln of truck vehicles miles traveled in a STAZ & -10.185 & 11.243 & 4.133 & 3.584 \\
\hline $\begin{array}{l}\text { Proportion of heavy } \\
\text { traffic }\end{array}$ & Total number of truck traffic/ Total number of vehicles in STAZ & 0.000 & 0.848 & 0.037 & 0.051 \\
\hline
\end{tabular}




\section{CHAPTER 5: EMPIRICAL ANALYSIS}

The results for the models described in Chapter 3 are presented in this chapter. Basically, the current study focused on two models: joint NB-MNLFS and multivariate RPNB model. The analysis was started by estimating separate univariate models for different crash types and total crash at STAZ level. After that, a multinomial fractional split (MNFLS) model was estimated for analyzing the crash proportions at zonal level by crash types. These models worked as a benchmark for the corresponding joint approaches (NB-MNLFS and Multivariate RPNB). All the models were estimated using the attributes described in chapter 4. Several functional forms and specification for different variables are explored. The appropriate functional form or specification was determined based on data fit. The final specification of the model development was based on removing the statistically insignificant variables in a systematic process based on $90 \%$ significance level.

\subsection{Model Specification and Overall Measure of Fit}

The empirical analysis involves estimation of four different models: 1) Independent NB-MNLFS model, 2) Joint NB-MNLFS model with correlation, 3) Independent Multivariate NB model, 4) Multivariate NB model with correlation. The log-likelihood values at convergence are estimated as follows: (1) Independent NB-MNLFS model (52 parameters) is $-53858.29^{5}$, (2) Joint NB-MNLFS model with correlation (55 parameters) is -53843.04 , (3) Independent Multivariate RPNB model (116 parameters) is -163958.22 and (4) Random Parameter Multivariate NB model with correlation (116 parameters) is -160953.57 . From the log-likelihood values we can see that the joint and multivariate models performed better than

\footnotetext{
5 The reader would note that the log-likelihood values for the fractional split models refers to the quasi loglikelihood values.
} 
their respective independent models. The estimation results of the joint NB-MNLFS model results are discussed in detail. However, the estimation results of multivariate NB model (shown in Table 5.2) are not discussed for the sake of brevity. The reader can also review the model estimates for Independent NB-MNLFS model and Random Parameter Multivariate NB model without correlation in Appendix A.

\subsection{NB-MNL Fractional Split Joint Model}

Table 5.3 presents the model estimation results of the joint NB-MNL fractional split model with NB for the total crash component and MNL fractional split for the proportion of crashes by collision type. The second column provides the results of the NB component while columns 3 through 10 present the results of the MNL fractional split model. The model results are discussed separately for total crash component and proportion by collision type.

\subsubsection{NB Component (Total Crash)}

A positive (negative) sign for a variable in the crash count component of Table 5.3 indicates that an increase in the variable is likely to result in more (less) motor vehicle crashes. The reader would note that in crash frequency models, area of the STAZ is used as an offset.

\subsubsection{Roadway Characteristics:}

The parameter estimates for proportion of arterial roads indicate that risk of motor vehicle crashes increases with increasing proportion of arterial roads in the STAZ. A similar result is observed for the proportion of urban roads (see Abdel-Aty and Radwan, 2000 for a similar result). Intersection density variable exhibits a positive impact on motorized crashes; an expected result because intersections are likely to increase potential vehicle conflicts due to the high number of turning movements (see Abdel-Aty et al., 2013, 2005). An increased 
proportion of roads with three or more lanes at the zonal level is found to be positively associated with motor vehicle crash incidence. The result is intuitive because higher number of lanes result in lane changing movements that could potentially lead to vehicle conflicts and crashes. The coefficient for mean posted speed limit in the zone has a negative coefficient indicating a reduction in crash incidence. The result is indicative of better roadway facility condition and design for high speed facilities (see Milton and Mannering, 1998 for a similar result). An increase in the length of divided roads in a STAZ reduces crash incidence. Divided roads reduce vehicle conflicts and are likely to reduce crash risk. The variables average inside and outside shoulder width offer contrasting effects. While an increase in average inside shoulder width is associated with higher crash risk, an increase in average outside shoulder width is likely to improve safety for motor vehicles. An increase in sidewalk width is associated with increased crash risk. The result warrants further investigation.

\subsubsection{Land-Use Attributes:}

As expected, large proportion of urban area is associated with increased incidence of traffic crashes. The urban area proportion serves as a surrogate for exposure - urban areas attract larger amount of traffic and thus increase crash risk. On the other hand, land use mix variable highlights how zones exhibiting high mixture of residential, industrial, institutional and other areas are likely to reduce driving speeds and reduce motor vehicle crash risk. No significant impact was found for other land use attributes in the analysis.

\subsubsection{Traffic Characteristics:}

The traffic volume variables representing AADT and Truck AADT offer expected results. With increase in AADT and truck AADT in the STAZ, the incidence of traffic crashes is likely to increase. 


\subsubsection{MNL Fractional Split Component}

In the MNL fractional split model, one of the outcomes must be the base for every variable for the sake of identification. In our analysis, fraction of rear-end crashes is considered as the base alternative for model estimation. Therefore, a positive (negative) sign for a variable indicates that an increase in the variable is likely to result in higher proportion of crashes for the corresponding alternative relative to the rear-end fraction. For rear-end crash proportions, impact of some exogenous variables is estimated and, in those cases,, other alternatives are considered as the base alternatives.

\subsubsection{Roadway Characteristics:}

With higher proportion of arterial roads, the proportion of rear-end and sideswipe crashes increases while the proportion of off-road crashes decreases. The result is indicative of higher traffic and associated likelihood of traffic conflicts with vehicles in the same direction leading to rear-end and sideswipe crashes. With increasing proportion of urban roads, the results indicate a reduction in the proportion of off-road and rollover crashes. A positive association is observed for the intersection density variable in the proportion of angular, sideswipe and other multiple vehicle crash categories while a negative association is observed for off-road and rollover crash proportions. At intersections, there are complicated turning movements that result in more angular and sideswipe crashes rather than off-road and roll over crashes.

The parameter for proportion of 3 or more lane roads reveals a positive association with sideswipe crash proportion. As expected, average posted speed limit in a zone is positively associated with head-on, off-road and angular crash proportions (see Ye et al., 2009 for similar result for head-on crashes). The result is contrary to the impact of the variable in the total crash component. The length of divided road in a STAZ is found to negatively influence off-road 
and sideswipe crash proportions. The average width of inside shoulder variable indicates a negative impact on proportion of head-on crashes. The result is expected because increasing width of inside shoulder reduces the potential for head-on collisions. In terms of outside shoulder width variable, the influence is positive for off-road, other single vehicle and rollover crash proportions. Average width of sidewalk variable negatively affects the proportion of offroad and rollover crashes.

\subsubsection{Land-Use Attributes:}

In terms of land use attributes, only proportion of urban area variable has significant impact on crash proportions. The likelihood of rear-end crashes increases for a high percentage of urbanized area in a STAZ while off-road, rollover and other single vehicle crash proportion reduces. The result seems reasonable because in urbanized area, there is high density of slow moving vehicles with reduced gap and as a result more rear-end crashes are likely to occur.

\subsubsection{Traffic Characteristics:}

The estimated AADT variable implies a positive effect on rear-end crash proportions and a negative effect on other single vehicle crash proportions. The result is intuitive as with higher number of vehicles, the likelihood of rear-end crashes increase. Truck AADT is negatively associated with off-road and rollover crash proportions. The result suggests that offroad and rollover crashes goes down with the increasing portion of trucks on the road.

\subsection{3 $\underline{\text { Common Unobserved Effects }}$}

Second last row panel of Table 5.3 represent the significance of unobserved effects in the joint NB-MNLFS model. Two sets of effects are tested in our analysis: (1) the common unobserved factors jointly affecting total crashes and the fractional split model (corresponding 
to $\psi_{i j}$ in the model system in Section 3.2) and (2) testing for the presence of parameter heterogeneity for different variables - also referred to as random effects - (corresponding to $\zeta_{i j}$ and $\varrho_{i}$ in Section 3.2). One common unobserved factor was found to be significant. The parameter represents common correlation between total crash and crash proportions of all collision types except the off-road category which acts as a base for this particular correlation analysis. As shown in Equation 9 of Section 3.2, the correlation between the two components could be either positive or negative. In our analysis, we found the positive sign to offer better fit for common correlation between total crash and crash proportions of rear end, head-on, angular, other single and multiple vehicle, rollover and sideswipe collision types. Overall, the results clearly support our hypothesis that common unobserved factors influence the two components.

\subsubsection{Random Effects}

In terms of random effects, we found that the proportion of urban area and average posted speed limit have significant variability in the total crash model. We did not find any significant random effects in the fractional split component. The results illustrate the need to consider parameter heterogeneity in the model frameworks.

\subsection{Summary}

The results from the empirical analysis are presented in this chapter. The joint NBMNLFS model results highlight the presence of common unobserved effects affecting the two components of the joint model as well as the presence of parameter heterogeneity. The comparison exercise of the proposed model with the traditional Multivariate NB model is discussed in the subsequent chapter. 
Table 5.1 Joint NB-MNLFS Model Estimation Results

\begin{tabular}{|c|c|c|c|c|c|c|c|c|c|}
\hline Joint Component & NB Model & \multicolumn{8}{|c|}{ MNLFS Model (Proportions) } \\
\hline Crash Type & Total Crash & Rear-end & Head-on & Angular & Off-Road & $\begin{array}{c}\text { Other } \\
\text { Single } \\
\text { Vehicle }\end{array}$ & $\begin{array}{c}\text { Other } \\
\text { Multiple } \\
\text { Vehicle }\end{array}$ & Rollover & Sideswipe \\
\hline Variable Name & $\begin{array}{c}\text { Estimate } \\
(\text { S.E. })^{*} \\
\end{array}$ & $\begin{array}{c}\text { Estimate } \\
\text { (S.E) }\end{array}$ & $\begin{array}{l}\text { Estimate } \\
\text { (S.E) }\end{array}$ & $\begin{array}{l}\text { Estimate } \\
\text { (S.E) }\end{array}$ & $\begin{array}{l}\text { Estimate } \\
\text { (S.E) }\end{array}$ & $\begin{array}{c}\text { Estimate } \\
\text { (S.E) }\end{array}$ & $\begin{array}{c}\text { Estimate } \\
\text { (S.E) }\end{array}$ & $\begin{array}{c}\text { Estimate } \\
\text { (S.E) }\end{array}$ & $\begin{array}{c}\text { Estimate } \\
\text { (S.E) }\end{array}$ \\
\hline Constant & $\begin{array}{c}-13.568 \\
(0.123) \\
\end{array}$ & --- & $\begin{array}{l}-1.280 \\
(0.367) \\
\end{array}$ & $\begin{array}{c}0.301 \\
(0.235) \\
\end{array}$ & $\begin{array}{c}1.410 \\
(0.260) \\
\end{array}$ & $\begin{array}{c}0.790 \\
(0.326) \\
\end{array}$ & $\begin{array}{c}0.865 \\
(0.215) \\
\end{array}$ & $\begin{array}{l}-0.233 \\
(0.467) \\
\end{array}$ & $\begin{array}{c}0.290 \\
(0.225) \\
\end{array}$ \\
\hline \multicolumn{10}{|l|}{ Roadway Characteristic } \\
\hline Proportion of arterial road & $\begin{array}{c}0.96 \\
(0.052)\end{array}$ & $\begin{array}{c}0.336 \\
(0.078)\end{array}$ & --- & --- & $\begin{array}{l}-0.186 \\
(0.109)\end{array}$ & --- & --- & --- & $\begin{array}{c}0.455 \\
(0.115)\end{array}$ \\
\hline Proportion of urban road & $\begin{array}{c}0.629 \\
(0.094)\end{array}$ & --- & --- & --- & $\begin{array}{l}-0.458 \\
(0.169)\end{array}$ & --- & --- & $\begin{array}{l}-0.729 \\
(0.362)\end{array}$ & --- \\
\hline Intersection density & $\begin{array}{c}0.536 \\
(0.022)\end{array}$ & --- & --- & $\begin{array}{l}0.299 \\
(0.04)\end{array}$ & $\begin{array}{l}-0.094 \\
(0.049)\end{array}$ & --- & $\begin{array}{c}0.199 \\
(0.039)\end{array}$ & $\begin{array}{l}-0.181 \\
(0.105)\end{array}$ & $\begin{array}{c}0.105 \\
(0.047)\end{array}$ \\
\hline $\begin{array}{l}\text { Proportion of road length } \\
\text { with } 3 \text { or more lanes }\end{array}$ & $\begin{array}{c}0.660 \\
(0.061)\end{array}$ & --- & --- & --- & --- & --- & --- & --- & $\begin{array}{c}0.541 \\
(0.113)\end{array}$ \\
\hline $\begin{array}{l}\text { Average posted speed } \\
\text { limit }\end{array}$ & $\begin{array}{l}-0.192 \\
(0.022)\end{array}$ & --- & $\begin{array}{c}0.179 \\
(0.087)\end{array}$ & $\begin{array}{c}0.094 \\
(0.034)\end{array}$ & $\begin{array}{c}0.113 \\
(0.038)\end{array}$ & --- & --- & --- & --- \\
\hline Standard deviation & $\begin{array}{l}0.090 \\
(0.010)\end{array}$ & & & & & & & & \\
\hline Divided road length & $\begin{array}{l}-0.113 \\
(0.008)\end{array}$ & --- & --- & --- & $\begin{array}{l}-0.022 \\
(0.011)\end{array}$ & --- & --- & --- & $\begin{array}{c}-0.04 \\
(0.012)\end{array}$ \\
\hline $\begin{array}{l}\text { Average inside shoulder } \\
\text { width }\end{array}$ & $\begin{array}{c}0.148 \\
(0.035) \\
\end{array}$ & --- & $\begin{array}{l}-0.305 \\
(0.141)\end{array}$ & --- & --- & --- & --- & --- & --- \\
\hline $\begin{array}{l}\text { Average outside shoulder } \\
\text { width }\end{array}$ & $\begin{array}{c}-0.739 \\
(0.044)\end{array}$ & --- & --- & --- & $\begin{array}{c}0.321 \\
(0.092)\end{array}$ & $\begin{array}{c}0.404 \\
(0.119) \\
\end{array}$ & --- & $\begin{array}{c}0.668 \\
(0.227)\end{array}$ & --- \\
\hline Average sidewalk width & $\begin{array}{c}0.172 \\
(0.027)\end{array}$ & --- & --- & --- & $\begin{array}{l}-0.114 \\
(0.050)\end{array}$ & --- & --- & $\begin{array}{l}-0.211 \\
(0.102)\end{array}$ & --- \\
\hline
\end{tabular}




\begin{tabular}{|c|c|c|c|c|c|c|c|c|c|}
\hline Joint Component & $\begin{array}{l}\text { NB Model } \\
\text { (Counts) }\end{array}$ & \multicolumn{8}{|c|}{ MNLFS Model (Proportions) } \\
\hline Crash Type & Total Crash & Rear-end & Head-on & Angular & Off-Road & $\begin{array}{c}\text { Other } \\
\text { Single } \\
\text { Vehicle }\end{array}$ & $\begin{array}{c}\text { Other } \\
\text { Multiple } \\
\text { Vehicle } \\
\end{array}$ & Rollover & Sideswipe \\
\hline Variable Name & $\begin{array}{c}\text { Estimate } \\
(\text { S.E) })^{*} \\
\end{array}$ & $\begin{array}{c}\text { Estimate } \\
\text { (S.E) }\end{array}$ & $\begin{array}{c}\text { Estimate } \\
\text { (S.E) }\end{array}$ & $\begin{array}{c}\text { Estimate } \\
\text { (S.E) } \\
\end{array}$ & $\begin{array}{c}\text { Estimate } \\
\text { (S.E) }\end{array}$ & $\begin{array}{c}\text { Estimate } \\
\text { (S.E) } \\
\end{array}$ & $\begin{array}{c}\text { Estimate } \\
\text { (S.E) } \\
\end{array}$ & $\begin{array}{c}\text { Estimate } \\
\text { (S.E) } \\
\end{array}$ & $\begin{array}{c}\text { Estimate } \\
\text { (S.E) } \\
\end{array}$ \\
\hline Proportion of urban area & $\begin{array}{c}2.525 \\
(0.088) \\
\end{array}$ & $\begin{array}{c}0.178 \\
(0.083)\end{array}$ & --- & --- & $\begin{array}{c}-0.580 \\
(0.163) \\
\end{array}$ & $\begin{array}{c}-0.862 \\
(0.120) \\
\end{array}$ & --- & $\begin{array}{c}-1.207 \\
(0.362) \\
\end{array}$ & --- \\
\hline Standard deviation & $\begin{array}{c}0.258 \\
(0.050) \\
\end{array}$ & & & & & & & & \\
\hline Land use mix & $\begin{array}{l}-1.454 \\
(0.117)\end{array}$ & --- & --- & --- & --- & --- & --- & --- & --- \\
\hline \multicolumn{10}{|l|}{ Traffic Characteristic } \\
\hline AADT & $\begin{array}{c}0.101 \\
(0.015)\end{array}$ & $\begin{array}{c}0.133 \\
(0.021)\end{array}$ & --- & --- & --- & $\begin{array}{c}-0.065 \\
(0.027)\end{array}$ & --- & --- & --- \\
\hline Truck AADT & $\begin{array}{c}0.023 \\
(0.005)\end{array}$ & --- & --- & --- & $\begin{array}{l}-0.040 \\
(0.010)\end{array}$ & --- & --- & $\begin{array}{l}-0.040 \\
(0.022)\end{array}$ & --- \\
\hline Dispersion parameter & $\begin{array}{c}1.919 \\
(0.028) \\
\end{array}$ & --- & --- & --- & --- & --- & --- & --- & --- \\
\hline Correlation & $\begin{array}{c}0.184 \\
(0.049) \\
\end{array}$ & $\begin{array}{c}0.184 \\
(0.049) \\
\end{array}$ & $\begin{array}{c}0.184 \\
(0.049) \\
\end{array}$ & $\begin{array}{c}0.184 \\
(0.049) \\
\end{array}$ & --- & $\begin{array}{c}0.184 \\
(0.049) \\
\end{array}$ & $\begin{array}{c}0.184 \\
(0.049) \\
\end{array}$ & $\begin{array}{c}0.184 \\
(0.049) \\
\end{array}$ & $\begin{array}{c}0.184 \\
(0.049) \\
\end{array}$ \\
\hline
\end{tabular}

Note: ${ }^{*}$ S.E. = Standard Error 
Table 5.2 Multivariate NB Model Results

\begin{tabular}{|c|c|c|c|c|c|c|c|c|}
\hline Crash Type & Rear-end & Head-on & Angular & Off-Road & $\begin{array}{c}\text { Other } \\
\text { Single } \\
\text { Vehicle } \\
\end{array}$ & $\begin{array}{c}\text { Other } \\
\text { Multiple } \\
\text { Vehicle } \\
\end{array}$ & Rollover & Sideswipe \\
\hline Variable Name & $\begin{array}{c}\text { Estimate } \\
(\text { S.E })^{*}\end{array}$ & $\begin{array}{l}\text { Estimate } \\
\text { (S.E) }\end{array}$ & $\begin{array}{l}\text { Estimate } \\
\text { (S.E) }\end{array}$ & $\begin{array}{c}\text { Estimate } \\
\text { (S.E) }\end{array}$ & $\begin{array}{l}\text { Estimate } \\
\text { (S.E) }\end{array}$ & $\begin{array}{l}\text { Estimate } \\
\text { (S.E) }\end{array}$ & $\begin{array}{l}\text { Estimate } \\
\text { (S.E) }\end{array}$ & $\begin{array}{c}\text { Estimate } \\
\text { (S.E) }\end{array}$ \\
\hline Constant & $\begin{array}{c}-16.550 \\
(0.134) \\
\end{array}$ & $\begin{array}{r}-19.723 \\
(0.258) \\
\end{array}$ & $\begin{array}{c}-17.476 \\
(0.142) \\
\end{array}$ & $\begin{array}{r}-16.704 \\
(0.135) \\
\end{array}$ & $\begin{array}{r}-17.283 \\
(0.158) \\
\end{array}$ & $\begin{array}{r}-16.343 \\
(0.133) \\
\end{array}$ & $\begin{array}{r}-19.372 \\
(0.279) \\
\end{array}$ & $\begin{array}{r}-17.433 \\
(0.157) \\
\end{array}$ \\
\hline \multicolumn{9}{|l|}{ Roadway Characteristic } \\
\hline Proportion of arterial road & $\begin{array}{c}0.964 \\
(0.051)\end{array}$ & $\begin{array}{c}0.568 \\
(0.073)\end{array}$ & $\begin{array}{l}0.548 \\
(0.05)\end{array}$ & $\begin{array}{c}0.325 \\
(0.044)\end{array}$ & $\begin{array}{c}0.541 \\
(0.053)\end{array}$ & $\begin{array}{c}0.647 \\
(0.051)\end{array}$ & $\begin{array}{c}0.312 \\
(0.279)\end{array}$ & $\begin{array}{c}0.996 \\
(0.054)\end{array}$ \\
\hline Proportion of urban road & $\begin{array}{c}0.917 \\
(0.099)\end{array}$ & $\begin{array}{c}0.892 \\
(0.164)\end{array}$ & $\begin{array}{l}1.003 \\
(0.10)\end{array}$ & $\begin{array}{c}0.574 \\
(0.085)\end{array}$ & $\begin{array}{c}0.636 \\
(0.103)\end{array}$ & $\begin{array}{c}1.009 \\
(0.099)\end{array}$ & -- & $\begin{array}{c}0.995 \\
(0.113)\end{array}$ \\
\hline Intersection density & $\begin{array}{c}0.508 \\
(0.024)\end{array}$ & $\begin{array}{c}0.784 \\
(0.039)\end{array}$ & $\begin{array}{c}0.861 \\
(0.023)\end{array}$ & $\begin{array}{c}0.408 \\
(0.021)\end{array}$ & $\begin{array}{c}0.604 \\
(0.026)\end{array}$ & $\begin{array}{c}0.705 \\
(0.024)\end{array}$ & $\begin{array}{c}0.396 \\
(0.038)\end{array}$ & $\begin{array}{c}0.577 \\
(0.026)\end{array}$ \\
\hline $\begin{array}{l}\text { Proportion of road length with } 3 \\
\text { or more lanes }\end{array}$ & $\begin{array}{c}0.738 \\
(0.059)\end{array}$ & $\begin{array}{c}0.740 \\
(0.079)\end{array}$ & $\begin{array}{c}0.638 \\
(0.055)\end{array}$ & $\begin{array}{l}0.356 \\
(0.05)\end{array}$ & $\begin{array}{c}0.512 \\
(0.058)\end{array}$ & $\begin{array}{c}0.902 \\
(0.057)\end{array}$ & $\begin{array}{c}0.401 \\
(0.084)\end{array}$ & $\begin{array}{r}1.135 \\
(0.06)\end{array}$ \\
\hline Average posted speed limit & $\begin{array}{l}-0.208 \\
(0.021)\end{array}$ & $\begin{array}{l}-0.137 \\
(0.031)\end{array}$ & $\begin{array}{l}-0.145 \\
(0.02)\end{array}$ & $\begin{array}{l}-0.076 \\
(0.017)\end{array}$ & $\begin{array}{l}-0.202 \\
(0.021)\end{array}$ & $\begin{array}{l}-0.259 \\
(0.021)\end{array}$ & $\begin{array}{l}-0.144 \\
(0.03)\end{array}$ & $\begin{array}{l}-0.251 \\
(0.022)\end{array}$ \\
\hline Divided road length & $\begin{array}{l}-0.043 \\
(0.008)\end{array}$ & $\begin{array}{l}-0.092 \\
(0.012)\end{array}$ & $\begin{array}{c}-0.09 \\
(0.007)\end{array}$ & $\begin{array}{c}-0.058 \\
(0.007)\end{array}$ & $\begin{array}{c}-0.072 \\
(0.008)\end{array}$ & $\begin{array}{c}-0.078 \\
(0.007)\end{array}$ & $\begin{array}{l}-0.024 \\
(0.012)\end{array}$ & $\begin{array}{l}-0.142 \\
(0.008)\end{array}$ \\
\hline Average inside shoulder width & $\begin{array}{c}0.173 \\
(0.035)\end{array}$ & $\begin{array}{l}-0.267 \\
(0.052)\end{array}$ & -- & $\begin{array}{c}0.191 \\
(0.029)\end{array}$ & $\begin{array}{c}0.16 \\
(0.036)\end{array}$ & $\begin{array}{c}0.064 \\
(0.035)\end{array}$ & $\begin{array}{c}0.18 \\
(0.049)\end{array}$ & $\begin{array}{c}0.203 \\
(0.037)\end{array}$ \\
\hline Average outside shoulder width & $\begin{array}{l}-0.856 \\
(0.044)\end{array}$ & $\begin{array}{c}-0.534 \\
(0.064)\end{array}$ & $\begin{array}{l}-0.781 \\
(0.042)\end{array}$ & $\begin{array}{l}-0.541 \\
(0.038)\end{array}$ & $\begin{array}{l}-0.577 \\
(0.045)\end{array}$ & $\begin{array}{l}-0.796 \\
(0.043)\end{array}$ & $\begin{array}{l}-0.234 \\
(0.067)\end{array}$ & $\begin{array}{c}-0.92 \\
(0.046)\end{array}$ \\
\hline Average sidewalk width & $\begin{array}{c}0.176 \\
(0.028) \\
\end{array}$ & $\begin{array}{c}0.263 \\
(0.043) \\
\end{array}$ & $\begin{array}{c}0.212 \\
(0.027) \\
\end{array}$ & -- & $\begin{array}{c}0.099 \\
(0.029) \\
\end{array}$ & $\begin{array}{c}0.283 \\
(0.027) \\
\end{array}$ & $\begin{array}{c}-0.166 \\
(0.038) \\
\end{array}$ & $\begin{array}{c}0.20 \\
(0.03) \\
\end{array}$ \\
\hline \multicolumn{9}{|l|}{ Land Use Attribute } \\
\hline Proportion of urban area & $\begin{array}{c}2.745 \\
(0.089)\end{array}$ & $\begin{array}{c}2.112 \\
(0.139)\end{array}$ & $\begin{array}{c}2.406 \\
(0.089)\end{array}$ & $\begin{array}{c}1.697 \\
(0.076)\end{array}$ & $\begin{array}{c}1.539 \\
(0.091)\end{array}$ & $\begin{array}{c}2.46 \\
(0.089)\end{array}$ & $\begin{array}{c}1.168 \\
(0.079)\end{array}$ & $\begin{array}{c}2.503 \\
(0.099)\end{array}$ \\
\hline Land use mix & $\begin{array}{l}-1.105 \\
(0.114)\end{array}$ & $\begin{array}{l}-1.813 \\
(0.155)\end{array}$ & $\begin{array}{l}-1.154 \\
(0.109)\end{array}$ & $\begin{array}{l}-1.378 \\
(0.095)\end{array}$ & $\begin{array}{l}-0.248 \\
(0.106)\end{array}$ & $\begin{array}{l}-1.127 \\
(0.112)\end{array}$ & $\begin{array}{l}-1.092 \\
(0.154)\end{array}$ & $\begin{array}{l}-1.244 \\
(0.118)\end{array}$ \\
\hline
\end{tabular}




\begin{tabular}{|c|c|c|c|c|c|c|c|c|}
\hline Crash Type & Rear-end & Head-on & Angular & Off-Road & $\begin{array}{c}\text { Other } \\
\text { Single } \\
\text { Vehicle }\end{array}$ & $\begin{array}{c}\text { Other } \\
\text { Multiple } \\
\text { Vehicle }\end{array}$ & Rollover & Sideswipe \\
\hline Variable Name & $\begin{array}{c}\text { Estimate } \\
\text { (S.E) }\end{array}$ & $\begin{array}{c}\text { Estimate } \\
\text { (S.E) }\end{array}$ & $\begin{array}{c}\text { Estimate } \\
\text { (S.E) }\end{array}$ & $\begin{array}{c}\text { Estimate } \\
\text { (S.E) }\end{array}$ & $\begin{array}{c}\text { Estimate } \\
\text { (S.E) }\end{array}$ & $\begin{array}{c}\text { Estimate } \\
\text { (S.E) }\end{array}$ & $\begin{array}{c}\text { Estimate } \\
\text { (S.E) }\end{array}$ & $\begin{array}{c}\text { Estimate } \\
\text { (S.E) }\end{array}$ \\
\hline AADT & $\begin{array}{c}0.162 \\
(0.016)\end{array}$ & $\begin{array}{c}0.125 \\
(0.029)\end{array}$ & $\begin{array}{c}0.167 \\
(0.017)\end{array}$ & $\begin{array}{c}0.14 \\
(0.016)\end{array}$ & $\begin{array}{c}0.109 \\
(0.018)\end{array}$ & $\begin{array}{c}0.10 \\
(0.016)\end{array}$ & $\begin{array}{c}0.219 \\
(0.031)\end{array}$ & $\begin{array}{c}0.189 \\
(0.018)\end{array}$ \\
\hline Truck AADT & $\begin{array}{c}0.026 \\
(0.005)\end{array}$ & $\begin{array}{c}0.074 \\
(0.007)\end{array}$ & $\begin{array}{c}0.025 \\
(0.005)\end{array}$ & -- & $\begin{array}{c}0.044 \\
(0.005)\end{array}$ & $\begin{array}{c}0.017 \\
(0.005)\end{array}$ & -- & $\begin{array}{c}0.044 \\
(0.005)\end{array}$ \\
\hline Dispersion parameter & $\begin{array}{c}0.764 \\
(0.023) \\
\end{array}$ & $\begin{array}{c}0.777 \\
(0.052) \\
\end{array}$ & $\begin{array}{c}0.538 \\
(0.024) \\
\end{array}$ & $\begin{array}{c}0.011 \\
(0.003) \\
\end{array}$ & $\begin{array}{l}0.226 \\
(0.03) \\
\end{array}$ & $\begin{array}{c}0.62 \\
(0.025) \\
\end{array}$ & $\begin{array}{c}0.286 \\
(0.049) \\
\end{array}$ & $\begin{array}{c}0.672 \\
(0.031) \\
\end{array}$ \\
\hline Correlation & $\begin{array}{c}1.025 \\
(0.009)\end{array}$ & $\begin{array}{c}1.025 \\
(0.009)\end{array}$ & $\begin{array}{c}1.025 \\
(0.009)\end{array}$ & $\begin{array}{c}1.025 \\
(0.009) \\
\end{array}$ & $\begin{array}{c}1.025 \\
(0.009)\end{array}$ & $\begin{array}{c}1.025 \\
(0.009) \\
\end{array}$ & $\begin{array}{c}1.025 \\
(0.009)\end{array}$ & $\begin{array}{c}1.025 \\
(0.009) \\
\end{array}$ \\
\hline
\end{tabular}

Note: ${ }^{*}$ S.E. = Standard Error 


\section{CHAPTER 6: COMPARISON EXERCISE}

The most common approach employed to model different collision types while addressing the potential unobserved heterogeneity across collision types is the development of multivariate crash frequency models. This research effort develops an alternative approach to accommodate for the presence of observed and unobserved heterogeneity across collision types by proposing a joint NB-MNLFS model. However, there has not been a comprehensive exercise between these two systems. The current study undertakes a first of its kind comparison exercise between the two approaches.

\subsection{Equivalent Log-Likelihood Measure}

The estimated multivariate NB model and the joint NB-MNLFS model fit measures (in term of log-likelihood or Information criterion) are not directly comparable. Therefore, in the current study context, we develop an equivalent approach for comparing the data fit measures of these two different frameworks. Specifically, we generate an equivalent log-likelihood of joint NB- MNLFS model which is directly comparable with the log-likelihood of the multivariate NB model. The exact equation for the computation of equivalent log-likelihood takes the following form:

$$
\begin{aligned}
& E L=\sum_{i}\left[\left(\ln \left\{P\left(c_{i K}\right)\right\}^{c_{i K}=0}\right)+\left(\mathcal{F}_{j} * \ln \left[\prod_{j=1}^{J}\left\{P\left(\mathbb{C}_{i j}\right)\right\}\right]^{c_{i K}>0}\right)\right], \text { with } \mathbb{C}_{i j}=\frac{c_{i j}}{E\left(y_{i j} \mid d_{i j}\right)} \text { and } \mathcal{F}_{j}= \\
& \frac{\ell_{S j}}{\ell_{S K}}
\end{aligned}
$$

where $i(i=1,2,3, \ldots, N)$ be the index for STAZ and $j(j=1,2,3, \ldots, J)$ is the index for different collision types. $c_{i j}$ is total number of observed crashes for collision type $j$ in STAZ $i$. $c_{i K}$ is total number of observed crashes in STAZ $i . E\left(y_{i j} \mid d_{i j}\right)$ is the expected proportion of crashes across different crash types computed by using Equation 9 from joint NB-MNLFS 
model. Thus, $\mathbb{C}_{i j}$ represents the predicted total number of crashes for STAZ $i$ by using predicted proportions from crash category $j . P\left(c_{i K}\right)$ is the probability for crash occurrence for total crash count $K$ (in Equation 1). Once we have $\mathbb{C}_{i j}$, we identified the predicted probabilities for $\mathbb{C}_{i j}$ from the probability equation of total crash count (as presented in Equation 1 for $P\left(c_{i K}\right)$ computation). By following this procedure, we ensure that the computed predicted probabilities accounts for total crash prediction errors from crash proportion predictions across all crash types considered. Further, $\mathcal{F}_{j}$ represents the weighting factor of log-likelihoods from independent NB model for different crash type $\left(\ell_{S j}\right)$ and for total crash $\left(\ell_{S K}\right)$. The computed equivalent log-likelihood for the joint NB-MNLFS model is -152126.87 . On the other hand, the computed log-likelihood at convergence for the multivariate NB model is -160953.57 . We can observe that the joint NB-MNLFS model offers better data fit with lower likelihood values relative to multivariate NB model. Thus, we can argue that the joint NB-MNLFS model outperforms the multivariate NB model in the current study context with substantially fewer parameters.

\subsection{Predictive Performance Evaluation}

We undertake an in-sample comparison exercise between the multivariate NB model and the joint NB-MNLFS model in terms of predictive performance by employing three different fit of measures: mean prediction bias (MPB), mean absolute deviation (MAD) and mean squared prediction error (MSPE). MPB represents the magnitude and direction of average bias in model prediction. The model with the lower MPB provides better prediction of the observed data and is computed as: 


$$
\mathrm{MPB}=\operatorname{mean}\left(\hat{y}_{i}-y_{i}\right)
$$

where, $\hat{y}_{i}$ and $y_{i}$ are the predicted and observed, number of crashes occurring over a period of time in a STAZ $i$ ( $i$ be the index for STAZ, $i=1,2,3, \ldots, 8518)$. On the other hand, MAD describes average misprediction of the estimated models. The model with lower MAD value closer to zero provides better average predictions of observed data. MAD is defined as:

$$
\mathrm{MAD}=\text { mean }\left|\hat{y}_{i}-y_{i}\right|
$$

Finally, MSPE quantifies the error associated with model predictions and is defined as:

$$
\operatorname{MSPE}=\operatorname{mean}\left(\hat{y}_{i}-y_{i}\right)^{2}
$$

The smaller the MSPE, the better the model predicts the observed data. These measures of fit are generated at disaggregate level: across all crash types and across all observations.

Table 6.1 presents the values for these three measures for multivariate NB and joint NB-MNLFS models. The results highlight that the joint NB-MNLFS model either outperforms or is very close to the multivariate model across the various measures computed. Specifically, based on MPB, we can conclude the multivariate negative binomial performs marginally better. For MAD and MSPE the joint NB-MNLFS model offers lower values compared to the multivariate NB model. The performance of the proposed model is particularly significant given the large difference in the number of parameters between the two specifications ( $55 \mathrm{vs}$ 116). The proposed joint model is substantially parsimonious and yet offers better data fit as indicated by the equivalent LL measure and the in-sample comparison. 


\subsection{Summary}

This chapter presented a first of its kind comparison exercise between the traditional Multivariate NB model and its fractional counterpart. To summarize, based on the empirical results, it is clear that the proposed joint NB-MNLFS model outperforms the commonly employed Random Parameter Multivariate NB model based on equivalent log-likelihood and prediction measures. 
Table 6.1 In-Sample Predictive Performance Measures

\begin{tabular}{|c|c|c|c|c|c|c|}
\hline & \multicolumn{2}{|c|}{$\begin{array}{c}\text { MPB } \\
\text { (Disaggregate level) }\end{array}$} & \multicolumn{2}{|c|}{$\begin{array}{c}\text { MAD } \\
\text { (Disaggregate level) }\end{array}$} & \multicolumn{2}{|c|}{$\begin{array}{c}\text { MSPE } \\
\text { (Disaggregate level) }\end{array}$} \\
\hline & $\begin{array}{c}\text { Multivariate } \\
\text { NB }\end{array}$ & $\begin{array}{l}\text { Joint NB- } \\
\text { MNLFS }\end{array}$ & $\begin{array}{c}\text { Multivariate } \\
\text { NB }\end{array}$ & $\begin{array}{c}\text { Joint } \\
\text { NB- } \\
\text { MNLFS }\end{array}$ & $\begin{array}{c}\text { Multivariate } \\
\text { NB }\end{array}$ & $\begin{array}{l}\text { Joint NB- } \\
\text { MNLFS }\end{array}$ \\
\hline \multicolumn{7}{|l|}{ Across Crash types } \\
\hline Rear-end & 36.98 & $\underline{29.260^{*}}$ & 49.163 & $\underline{37.607}$ & 48106.83 & $\underline{28078.053}$ \\
\hline Head-on & $\underline{0.764}$ & 1.968 & $\underline{2.114}$ & 2.871 & $\underline{75.292}$ & 78.661 \\
\hline Angular & $\underline{16.029}$ & 16.148 & 23.576 & $\underline{20.953}$ & 12469.626 & $\underline{12182.956}$ \\
\hline Off-road & $\underline{3.868}$ & 8.249 & $\underline{7.210}$ & 9.391 & $\underline{659.999}$ & 669.641 \\
\hline $\begin{array}{l}\text { Other-Single } \\
\text { Vehicle }\end{array}$ & $\underline{2.049}$ & 4.788 & $\underline{4.118}$ & 5.782 & $\underline{214.776}$ & 361.195 \\
\hline $\begin{array}{l}\text { Other-Multiple } \\
\text { Vehicle }\end{array}$ & $\underline{16.093}$ & 16.104 & 24.774 & $\underline{22.126}$ & $\underline{13961.63}$ & 16012.269 \\
\hline Rollover & $\underline{0.297}$ & 0.994 & $\underline{1.005}$ & 1.399 & 9.932 & 14.695 \\
\hline Sideswipe & 9.659 & $\underline{9.077}$ & 14.062 & $\underline{12.306}$ & $\underline{5483.989}$ & 5969.865 \\
\hline $\begin{array}{l}\text { Total (average error } \\
\text { across all collision } \\
\text { types) }\end{array}$ & $\underline{10.717}$ & 10.823 & 15.753 & $\underline{14.054}$ & 10122.759 & $\underline{7920.917}$ \\
\hline $\begin{array}{l}\text { Across Observation } \\
\text { (8518 records) }\end{array}$ & $\underline{85.739}$ & 86.588 & 126.020 & $\underline{112.434}$ & 80982.074 & $\underline{63367.335}$ \\
\hline
\end{tabular}

Note: * The better model is underlined and is in bold format 


\section{CHAPTER 7: CONCLUSIONS}

In recent years, there is growing recognition that common unobserved factors that influence crash frequency by one attribute level are also likely to influence crash frequency by other attribute levels for the same observation unit. The most common approach employed to address the potential unobserved heterogeneity in existing safety literature is the development of multivariate crash frequency models. In the current study, we formulated and estimated an alternative joint econometric framework to accommodate for the presence of unobserved heterogeneity - referred to as joint negative binomial-multinomial logit fractional split (NBMNLFS) model. Furthermore, a first of its kind comparison exercise between the most commonly used multivariate model (multivariate random parameter negative binomial model) and the proposed joint NB-MNLFS model was performed by generating equivalent loglikelihood measure.

In our current research effort, a joint NB-MNLFS approach was proposed to employ a crash frequency model for total crashes in conjunction with a fractional split model for proportion of crashes by different collision types. The study was conducted by using data from Florida at the Statewide Traffic Analysis Zone (STAZ) level for the year 2015 considering a host of exogenous variables including roadway characteristics, land use attributes and traffic characteristic for the model estimation. The findings highlighted the presence of common unobserved factors influencing total crash frequency and proportions by crash types. In terms of random effects, proportion of urban area and average posted speed limit revealed significant variability in the total crash count component of the proposed joint model.

A comprehensive comparison of the proposed model with the most commonly used multivariate negative binomial (NB) model was conducted. The joint and the multivariate models are not directly comparable because the joint model is estimated based on a quasi- 
likelihood system. To address this, an equivalent log-likelihood measure was generated for the proposed joint model. The equivalent log-likelihood value for the proposed approach was lower than the log-likelihood estimate for the multivariate NB model with a substantially fewer number of parameters. To investigate the comparison further, different fit measures were generated to compare the in-sample predictive performance of the two models. The result clearly highlighted the superiority of the proposed joint model with its parsimonious structure. The joint system proposed is suggested as a complementary approach to the traditional multivariate count modeling frameworks.

The thesis is not without limitations. It might be interesting to explore the transferability of models developed for crash count and crash type simultaneously by estimating similar models for multiple spatial units across several years. 
APPENDIX:

INDEPENDENT MODEL RESULTS 
Table A.1 Independent NB-MNLFS Model Results

\begin{tabular}{|c|c|c|c|c|c|c|c|c|c|}
\hline Joint Component & NB Model & \multicolumn{8}{|c|}{ MNLFS Model (Proportions) } \\
\hline Crash Type & Total Crash & Rear end & Head-on & Angle & Off-Road & $\begin{array}{l}\text { Other } \\
\text { Single } \\
\end{array}$ & $\begin{array}{c}\text { Other } \\
\text { Multiple } \\
\end{array}$ & Rollover & Sideswipe \\
\hline Variable Name & $\begin{array}{c}\text { Estimate } \\
\text { (S.D) } \\
\end{array}$ & $\begin{array}{c}\text { Estimate } \\
\text { (S.D) } \\
\end{array}$ & $\begin{array}{c}\text { Estimate } \\
\text { (S.D) } \\
\end{array}$ & $\begin{array}{c}\text { Estimate } \\
\text { (S.D) } \\
\end{array}$ & $\begin{array}{c}\text { Estimate } \\
\text { (S.D) } \\
\end{array}$ & $\begin{array}{c}\text { Estimate } \\
\text { (S.D) } \\
\end{array}$ & $\begin{array}{c}\text { Estimate } \\
\text { (S.D) } \\
\end{array}$ & $\begin{array}{c}\text { Estimate } \\
\text { (S.D) } \\
\end{array}$ & $\begin{array}{c}\text { Estimate } \\
\text { (S.D) } \\
\end{array}$ \\
\hline LTZM & $1.00(--)$ & --- & --- & --- & --- & --- & --- & --- & --- \\
\hline Constant & $\begin{array}{c}-13.361 \\
(0.31) \\
\end{array}$ & --- & $\begin{array}{l}-1.289 \\
(0.367)\end{array}$ & $\begin{array}{c}0.303 \\
(0.234) \\
\end{array}$ & $\begin{array}{c}1.401 \\
(0.259) \\
\end{array}$ & $\begin{array}{c}0.765 \\
(0.327) \\
\end{array}$ & $\begin{array}{c}0.858 \\
(0.215) \\
\end{array}$ & $\begin{array}{l}-0.238 \\
(0.47) \\
\end{array}$ & $\begin{array}{c}0.284 \\
(0.225) \\
\end{array}$ \\
\hline \multicolumn{10}{|l|}{ Roadway Characteristic } \\
\hline Proportion of arterial road & $\begin{array}{c}0.980 \\
(0.068)\end{array}$ & $\begin{array}{c}0.336 \\
(0.078)\end{array}$ & --- & --- & $\begin{array}{l}-0.187 \\
(0.109)\end{array}$ & --- & --- & --- & $\begin{array}{c}0.455 \\
(0.115)\end{array}$ \\
\hline Proportion of urban road & $\begin{array}{c}0.616 \\
(0.142)\end{array}$ & --- & --- & --- & $\begin{array}{l}-0.459 \\
(0.168)\end{array}$ & --- & --- & $\begin{array}{l}-0.730 \\
(0.363)\end{array}$ & --- \\
\hline Intersection density & $\begin{array}{c}0.530 \\
(0.035)\end{array}$ & --- & --- & $\begin{array}{l}0.299 \\
(0.04)\end{array}$ & $\begin{array}{l}-0.093 \\
(0.049)\end{array}$ & --- & $\begin{array}{c}0.199 \\
(0.039)\end{array}$ & $\begin{array}{l}-0.183 \\
(0.105)\end{array}$ & $\begin{array}{c}0.105 \\
(0.047)\end{array}$ \\
\hline $\begin{array}{l}\text { Proportion of road length } \\
\text { with } 3 \text { or more lanes }\end{array}$ & $\begin{array}{c}0.630 \\
(0.069)\end{array}$ & --- & --- & --- & --- & --- & --- & --- & $\begin{array}{c}0.542 \\
(0.113)\end{array}$ \\
\hline Average posted speed limit & $\begin{array}{l}-0.189 \\
(0.027)\end{array}$ & --- & $\begin{array}{c}0.180 \\
(0.087)\end{array}$ & $\begin{array}{c}0.093 \\
(0.034)\end{array}$ & $\begin{array}{c}0.113 \\
(0.038)\end{array}$ & --- & --- & --- & --- \\
\hline Divided road length & $\begin{array}{l}-0.122 \\
(0.009)\end{array}$ & --- & --- & --- & $\begin{array}{l}-0.022 \\
(0.011)\end{array}$ & --- & --- & --- & $\begin{array}{l}-0.040 \\
(0.012)\end{array}$ \\
\hline $\begin{array}{l}\text { Average inside shoulder } \\
\text { width }\end{array}$ & $\begin{array}{l}0.160 \\
(0.045)\end{array}$ & --- & $\begin{array}{l}-0.306 \\
(0.141)\end{array}$ & --- & --- & --- & --- & --- & --- \\
\hline $\begin{array}{l}\text { Average outside shoulder } \\
\text { width }\end{array}$ & $\begin{array}{l}-0.720 \\
(0.057) \\
\end{array}$ & --- & --- & --- & $\begin{array}{c}0.324 \\
(0.092) \\
\end{array}$ & $\begin{array}{c}0.408 \\
(0.119) \\
\end{array}$ & --- & $\begin{array}{c}0.668 \\
(0.228) \\
\end{array}$ & --- \\
\hline Average sidewalk width & $\begin{array}{l}0.165 \\
(0.035)\end{array}$ & --- & --- & --- & $\begin{array}{l}-0.112 \\
(0.05)\end{array}$ & --- & --- & $\begin{array}{l}-0.212 \\
(0.102)\end{array}$ & --- \\
\hline \multicolumn{10}{|l|}{ Built Environment } \\
\hline Proportion of urban area & $\begin{array}{c}2.536 \\
(0.123)\end{array}$ & $\begin{array}{c}0.179 \\
(0.083)\end{array}$ & --- & --- & $\begin{array}{l}-0.573 \\
(0.162)\end{array}$ & $\begin{array}{l}-0.859 \\
(0.12)\end{array}$ & --- & $\begin{array}{l}-1.201 \\
(0.362)\end{array}$ & --- \\
\hline
\end{tabular}




\begin{tabular}{|c|c|c|c|c|c|c|c|c|c|}
\hline Variable Name & $\begin{array}{l}\text { Estimate } \\
\text { (S.D) }\end{array}$ & $\begin{array}{c}\text { Estimate } \\
\text { (S.D) }\end{array}$ & $\begin{array}{l}\text { Estimate } \\
\text { (S.D) }\end{array}$ & $\begin{array}{c}\text { Estimate } \\
\text { (S.D) }\end{array}$ & $\begin{array}{c}\text { Estimate } \\
\text { (S.D) }\end{array}$ & $\begin{array}{l}\text { Estimate } \\
\text { (S.D) }\end{array}$ & $\begin{array}{c}\text { Estimate } \\
\text { (S.D) }\end{array}$ & $\begin{array}{c}\text { Estimate } \\
\text { (S.D) }\end{array}$ & $\begin{array}{c}\text { Estimate } \\
\text { (S.D) }\end{array}$ \\
\hline Land use mix & $\begin{array}{c}-1.562 \\
(0.104) \\
\end{array}$ & --- & --- & -- & --- & --- & --- & --- & --- \\
\hline \multicolumn{10}{|l|}{ Exposure Measure } \\
\hline AADT & $\begin{array}{c}0.092 \\
(0.031)\end{array}$ & $\begin{array}{c}0.132 \\
(0.021)\end{array}$ & --- & --- & --- & $\begin{array}{l}-0.064 \\
(0.027)\end{array}$ & --- & --- & --- \\
\hline Truck AADT & $\begin{array}{c}0.022 \\
(0.007)\end{array}$ & --- & --- & --- & $\begin{array}{l}-0.040 \\
(0.01)\end{array}$ & --- & --- & $\begin{array}{l}-0.040 \\
(0.022)\end{array}$ & --- \\
\hline Dispersion parameter & $\begin{array}{c}2.046 \\
(0.037)\end{array}$ & --- & --- & --- & --- & --- & --- & --- & --- \\
\hline
\end{tabular}


Table A.2 Independent Multivariate NB Model Results

\begin{tabular}{|c|c|c|c|c|c|c|c|c|}
\hline Crash Type & Rear end & Head-on & Angle & Off-Road & $\begin{array}{l}\text { Other } \\
\text { Single }\end{array}$ & $\begin{array}{c}\text { Other } \\
\text { Multiple }\end{array}$ & Rollover & Sideswipe \\
\hline Variable Name & $\begin{array}{l}\text { Estimate } \\
\text { (S.D) }\end{array}$ & $\begin{array}{c}\text { Estimate } \\
\text { (S.D) }\end{array}$ & $\begin{array}{c}\text { Estimate } \\
\text { (S.D) }\end{array}$ & $\begin{array}{c}\text { Estimate } \\
\text { (S.D) }\end{array}$ & $\begin{array}{c}\text { Estimate } \\
\text { (S.D) }\end{array}$ & $\begin{array}{c}\text { Estimate } \\
\text { (S.D) }\end{array}$ & $\begin{array}{c}\text { Estimate } \\
\text { (S.D) }\end{array}$ & $\begin{array}{c}\text { Estimate } \\
\text { (S.D) }\end{array}$ \\
\hline LTZM (Exposure Variable) & 1.00 & 1.00 & 1.00 & 1.00 & 1.00 & 1.00 & 1.00 & 1.00 \\
\hline Constant & $\begin{array}{c}-15.32 \\
(0.343) \\
\end{array}$ & $\begin{array}{c}-18.861 \\
(0.354) \\
\end{array}$ & $\begin{array}{c}-16.393 \\
(0.216) \\
\end{array}$ & $\begin{array}{c}-15.965 \\
(0.157) \\
\end{array}$ & $\begin{array}{c}-16.51 \\
(0.193) \\
\end{array}$ & $\begin{array}{l}-15.43 \\
(0.216) \\
\end{array}$ & $\begin{array}{c}-18.769 \\
(0.311) \\
\end{array}$ & $\begin{array}{c}-16.352 \\
(0.245) \\
\end{array}$ \\
\hline \multicolumn{9}{|l|}{ Roadway Characteristic } \\
\hline Proportion of arterial road & $\begin{array}{l}1.096 \\
(0.08)\end{array}$ & $\begin{array}{c}0.572 \\
(0.099)\end{array}$ & $\begin{array}{c}0.684 \\
(0.071)\end{array}$ & $\begin{array}{l}0.397 \\
(0.05)\end{array}$ & $\begin{array}{c}0.655 \\
(0.062)\end{array}$ & $\begin{array}{c}0.753 \\
(0.071)\end{array}$ & $\begin{array}{c}0.327 \\
(0.081)\end{array}$ & $\begin{array}{c}1.111 \\
(0.082)\end{array}$ \\
\hline Proportion of urban road & $\begin{array}{c}0.976 \\
(0.169)\end{array}$ & $\begin{array}{c}0.905 \\
(0.183)\end{array}$ & $\begin{array}{c}1.002 \\
(0.152)\end{array}$ & $\begin{array}{c}0.569 \\
(0.094)\end{array}$ & $\begin{array}{c}0.635 \\
(0.121)\end{array}$ & $\begin{array}{c}0.982 \\
(0.177)\end{array}$ & --- & $\begin{array}{c}1.053 \\
(0.148)\end{array}$ \\
\hline Intersection density & $\begin{array}{c}0.443 \\
(0.038)\end{array}$ & $\begin{array}{c}0.774 \\
(0.052)\end{array}$ & $\begin{array}{c}0.807 \\
(0.038)\end{array}$ & $\begin{array}{c}0.394 \\
(0.025)\end{array}$ & $\begin{array}{c}0.602 \\
(0.035)\end{array}$ & $\begin{array}{c}0.668 \\
(0.039)\end{array}$ & $\begin{array}{c}0.41 \\
(0.045)\end{array}$ & $\begin{array}{c}0.548 \\
(0.038)\end{array}$ \\
\hline $\begin{array}{l}\text { Proportion of road length with } \\
3 \text { or more lanes }\end{array}$ & $\begin{array}{c}0.625 \\
(0.077)\end{array}$ & $\begin{array}{c}0.63 \\
(0.103)\end{array}$ & $\begin{array}{c}0.613 \\
(0.069)\end{array}$ & $\begin{array}{c}0.336 \\
(0.054)\end{array}$ & $\begin{array}{c}0.494 \\
(0.067)\end{array}$ & $\begin{array}{c}0.815 \\
(0.078)\end{array}$ & $\begin{array}{c}0.427 \\
(0.093)\end{array}$ & $\begin{array}{c}1.106 \\
(0.088)\end{array}$ \\
\hline Average posted speed limit & $\begin{array}{l}-0.228 \\
(0.033)\end{array}$ & $\begin{array}{l}-0.117 \\
(0.036)\end{array}$ & $\begin{array}{l}-0.136 \\
(0.025)\end{array}$ & $\begin{array}{l}-0.099 \\
(0.019)\end{array}$ & $\begin{array}{l}-0.211 \\
(0.026)\end{array}$ & $\begin{array}{l}-0.286 \\
(0.033)\end{array}$ & $\begin{array}{l}-0.16 \\
(0.038)\end{array}$ & $\begin{array}{l}-0.267 \\
(0.036)\end{array}$ \\
\hline Divided road length & $\begin{array}{l}-0.066 \\
(0.011)\end{array}$ & $\begin{array}{l}-0.102 \\
(0.015)\end{array}$ & $\begin{array}{l}-0.123 \\
(0.01)\end{array}$ & $\begin{array}{l}-0.074 \\
(0.008)\end{array}$ & $\begin{array}{l}-0.088 \\
(0.01)\end{array}$ & $\begin{array}{l}-0.111 \\
(0.01)\end{array}$ & $\begin{array}{l}-0.034 \\
(0.013)\end{array}$ & $\begin{array}{l}-0.171 \\
(0.012)\end{array}$ \\
\hline Average inside shoulder width & $\begin{array}{c}0.176 \\
(0.051)\end{array}$ & $\begin{array}{l}-0.269 \\
(0.062)\end{array}$ & --- & $\begin{array}{c}0.239 \\
(0.033)\end{array}$ & $\begin{array}{c}0.188 \\
(0.041)\end{array}$ & $\begin{array}{c}0.145 \\
(0.051)\end{array}$ & $\begin{array}{c}0.165 \\
(0.051)\end{array}$ & $\begin{array}{l}0.208 \\
(0.05)\end{array}$ \\
\hline $\begin{array}{l}\text { Average outside shoulder } \\
\text { width }\end{array}$ & $\begin{array}{l}-0.747 \\
(0.069)\end{array}$ & $\begin{array}{l}-0.536 \\
(0.085)\end{array}$ & $\begin{array}{l}-0.746 \\
(0.054)\end{array}$ & $\begin{array}{l}-0.553 \\
(0.041)\end{array}$ & $\begin{array}{l}-0.589 \\
(0.052)\end{array}$ & $\begin{array}{l}-0.711 \\
(0.055)\end{array}$ & $\begin{array}{l}-0.295 \\
(0.084)\end{array}$ & $\begin{array}{l}-0.867 \\
(0.064)\end{array}$ \\
\hline Average sidewalk width & $\begin{array}{c}0.172 \\
(0.011) \\
\end{array}$ & $\begin{array}{c}0.285 \\
(0.051) \\
\end{array}$ & $\begin{array}{c}0.20 \\
(0.01) \\
\end{array}$ & --- & $\begin{array}{c}0.101 \\
(0.033) \\
\end{array}$ & $\begin{array}{c}0.265 \\
(0.042) \\
\end{array}$ & $\begin{array}{c}-0.19 \\
(0.041) \\
\end{array}$ & $\begin{array}{c}0.233 \\
(0.042) \\
\end{array}$ \\
\hline \multicolumn{9}{|l|}{ Built Environment } \\
\hline Proportion of urban area & $\begin{array}{c}2.737 \\
(0.146)\end{array}$ & $\begin{array}{c}2.28 \\
(0.158)\end{array}$ & $\begin{array}{c}2.481 \\
(0.126)\end{array}$ & $\begin{array}{c}1.691 \\
(0.083)\end{array}$ & $\begin{array}{c}1.546 \\
(0.099)\end{array}$ & $\begin{array}{c}2.544 \\
(0.149)\end{array}$ & $\begin{array}{c}1.204 \\
(0.079)\end{array}$ & $\begin{array}{c}2.603 \\
(0.122)\end{array}$ \\
\hline Land use mix & $\begin{array}{l}-1.467 \\
(0.112)\end{array}$ & $\begin{array}{l}-2.186 \\
(0.143)\end{array}$ & $\begin{array}{c}-1.472 \\
(0.10)\end{array}$ & $\begin{array}{l}-1.395 \\
(0.081)\end{array}$ & $\begin{array}{c}-0.416 \\
(0.10)\end{array}$ & $\begin{array}{l}-1.491 \\
(0.116)\end{array}$ & $\begin{array}{l}-1.21 \\
(0.161)\end{array}$ & $\begin{array}{l}-1.622 \\
(0.12)\end{array}$ \\
\hline
\end{tabular}




\begin{tabular}{|c|c|c|c|c|c|c|c|c|}
\hline Variable Name & $\begin{array}{c}\text { Estimate } \\
\text { (S.D) }\end{array}$ & $\begin{array}{c}\text { Estimate } \\
\text { (S.D) }\end{array}$ & $\begin{array}{c}\text { Estimate } \\
\text { (S.D) }\end{array}$ & $\begin{array}{c}\text { Estimate } \\
\text { (S.D) }\end{array}$ & $\begin{array}{c}\text { Estimate } \\
\text { (S.D) }\end{array}$ & $\begin{array}{c}\text { Estimate } \\
\text { (S.D) }\end{array}$ & $\begin{array}{c}\text { Estimate } \\
\text { (S.D) }\end{array}$ & $\begin{array}{c}\text { Estimate } \\
\text { (S.D) }\end{array}$ \\
\hline AADT & $\begin{array}{c}0.10 \\
(0.037)\end{array}$ & $\begin{array}{c}0.08 \\
(0.038)\end{array}$ & $\begin{array}{c}0.123 \\
(0.025)\end{array}$ & $\begin{array}{c}0.124 \\
(0.019)\end{array}$ & $\begin{array}{c}0.09 \\
(0.024)\end{array}$ & $\begin{array}{c}0.078 \\
(0.024)\end{array}$ & $\begin{array}{c}0.22 \\
(0.037)\end{array}$ & $\begin{array}{c}0.139 \\
(0.033)\end{array}$ \\
\hline Truck AADT & $\begin{array}{c}0.028 \\
(0.007)\end{array}$ & $\begin{array}{c}0.081 \\
(0.009)\end{array}$ & $\begin{array}{c}0.027 \\
(0.007)\end{array}$ & --- & $\begin{array}{c}0.04 \\
(0.006)\end{array}$ & $\begin{array}{c}0.016 \\
(0.007)\end{array}$ & $\begin{array}{c}0.014 \\
(0.008)\end{array}$ & $\begin{array}{c}0.046 \\
(0.007)\end{array}$ \\
\hline Dispersion parameter & $\begin{array}{c}1.548 \\
(0.044)\end{array}$ & $\begin{array}{l}1.963 \\
(0.08)\end{array}$ & $\begin{array}{c}1.377 \\
(0.034)\end{array}$ & $\begin{array}{c}0.723 \\
(0.021)\end{array}$ & $\begin{array}{c}1.06 \\
(0.033)\end{array}$ & $\begin{array}{c}1.507 \\
(0.035)\end{array}$ & $\begin{array}{c}1.284 \\
(0.076)\end{array}$ & $\begin{array}{c}1.646 \\
(0.042)\end{array}$ \\
\hline
\end{tabular}




\section{REFERENCES}

Abdel-Aty, M.A., Radwan, A.E., 2000. Modeling traffic accident occurrence and involvement. Accident Analysis and Prevention 32(5), 633-642.

Abdel-Aty, M., Keller, J., Brady, P., 2005. Analysis of types of crashes at signalized intersections by using complete crash data and tree-based regression. Transportation Research Record: Journal of the Transportation Research Board 1908, 37-45.

Abdel-Aty, M., Lee, J., Siddiqui, C., Choi, K., 2013. Geographical unit based analysis in the context of transportation safety planning. Transportation Research Part A: Policy and Practice 49, 62-75.

Aguero-Valverde, J., Wu, K.-F.K., Donnell, E.T., 2016. A multivariate spatial crash frequency model for identifying sites with promise based on crash types. Accident Analysis and Prevention 87, 8-16.

Anastasopoulos, P.C., 2016. Random parameters multivariate tobit and zero-inflated count data models: addressing unobserved and zero-state heterogeneity in accident injury-severity rate and frequency analysis. Analytic Methods in Accident Research 11, 17-32.

Aptech 2015, Aptech Systems Inc, URL http://www.aptech.com/ (accessed 9.19.15).

Bhat, C.R., 2001. Quasi-random maximum simulated likelihood estimation of the mixed multinomial logit model. Transportation Research Part B: Methodological 35 (7), 677693.

Chai, C., Wong, Y.D., 2014. Micro-simulation of vehicle conflicts involving right-turn vehicles at signalized intersections based on cellular automata. Accident Analysis and Prevention 63, 94-103. 
Cheng, W., Gill, G.S., Dasu, R., Xie, M., Jia, X., Zhou, J., 2017. Comparison of Multivariate Poisson lognormal spatial and temporal crash models to identify hot spots of intersections based on crash types. Accident Analysis and Prevention 99, 330-341.

Chiou, Y.-C., Fu, C., 2015. Modeling crash frequency and severity with spatiotemporal dependence. Analytic Methods in Accident Research 5, 43-58.

Chiou, Y.-C., Fu, C., 2013. Modeling crash frequency and severity using multinomialgeneralized Poisson model with error components. Accident Analysis and Prevention 50, $73-82$.

Chiou, Y.-C., Fu, C., Chih-Wei, H., 2014. Incorporating spatial dependence in simultaneously modeling crash frequency and severity. Analytic Methods in Accident Research 2, 1-11.

Eluru, N., Bhat, C.R., Hensher, D.A., 2008. A mixed generalized ordered response model for examining pedestrian and bicyclist injury severity level in traffic crashes. Accident Analysis and Prevention 40, 1033-1054.

Eluru, N., Chakour, V., Chamberlain, M., Miranda-Moreno, L.F., 2013. Modeling vehicle operating speed on urban roads in Montreal: a panel mixed ordered probit fractional split model. Accident Analysis and Prevention 59, 125-134.

Geedipally, S., Patil, S., Lord, D., 2010. Examination of methods to estimate crash counts by collision type. Transportation Research Record: Journal of the Transportation Research Board 2165, 12-20.

Heydari, S., Fu, L., Miranda-Moreno, L.F., Joseph, L., 2017. Using a flexible multivariate latent class approach to model correlated outcomes: a joint analysis of pedestrian and cyclist injuries. Analytic Methods in Accident Research 13, 16-27.

Ivan, J.N., Wang, C., Bernardo, N.R., 2000. Explaining two-lane highway crash rates using land use and hourly exposure. Accident Analysis and Prevention 32(6), 787-795. 
Lee, J., Yasmin, S., Eluru, N., Abdel-Aty, M., Cai, Q., 2018. Macroscopic Analysis of Crash Proportion by Mode: Fractional Split Multinomial Logit Modeling Approach, Accident Analysis and Prevention 111, 12-22.

Li, X., Yan, X., Wu, J., Radwan, E., Zhang, Y., 2016. A rear-end collision risk assessment model based on drivers' collision avoidance process under influences of cell phone use and gender-A driving simulator based study. Accident Analysis and Prevention 97, 118.

Lord, D., Mannering, F., 2010. The statistical analysis of crash-frequency data: a review and assessment of methodological alternatives. Transportation Research Part A: Policy and Practice 44(5), 291-305.

Mannering, F.L., Shankar, V., Bhat, C.R., 2016. Unobserved heterogeneity and the statistical analysis of highway accident data. Analytic Methods in Accident Research 11, 1-16.

Milton, J., Mannering, F., 1998. The relationship among highway geometrics, traffic-related elements and motor-vehicle accident frequencies. Transportation 25(4), 395-413.

Milton, J.C., Shankar, V.N., Mannering, F.L., 2008. Highway accident severities and the mixed logit model: an exploratory empirical analysis. Accident Analysis and Prevention 40(1), $260-266$.

Mothafer, G.I., Yamamoto, T., Shankar, V.N., 2016. Evaluating crash type covariances and roadway geometric marginal effects using the multivariate Poisson gamma mixture model. Analytic Methods in Accident Research 9, 16-26.

Nashad, T., Yasmin, S., Eluru, N., Lee, J., Abdel-Aty, M.A., 2016. Joint modeling of pedestrian and bicycle crashes: copula-based approach. Transportation Research Record: Journal of the Transportation Research Board 2601, 119-127. 
Papke, L.E., Wooldridge, J.M., 1996. Econometric methods for fractional response variables with an application to $401(\mathrm{k})$ plan participation rates. Journal of Applied Econometrics 11(6), 619-632.

Persaud, B.N., Mucsi, K., 1995. Microscopic accident potential models for two-lane rural roads. Transportation Research Record 1485, 134-139.

Qin, X., Ivan, J.N., Ravishanker, N., 2004. Selecting exposure measures in crash rate prediction for two-lane highway segments. Accident Analysis and Prevention 36(2), 183-191.

Serhiyenko, V., Mamun, S.A., Ivan, J.N., Ravishanker, N., 2016. Fast Bayesian inference for modeling multivariate crash counts. Analytic Methods in Accident Research 9, 44-53.

Wang, K., Ivan, J.N., Ravishanker, N., Jackson, E., 2017. Multivariate poisson lognormal modeling of crashes by type and severity on rural two lane highways. Accident Analysis and Prevention 99, 6-19.

Wang, X., Abdel-Aty, M., 2008a. Modeling left-turn crash occurrence at signalized intersections by conflicting patterns. Accident Analysis and Prevention 40(1), 76-88.

Wang, X., Abdel-Aty, M., 2008b. Analysis of left-turn crash injury severity by conflicting pattern using partial proportional odds models. Accident Analysis and Prevention 40(5), $1674-1682$.

Wang, X., Abdel-Aty, M., 2006. Temporal and spatial analyses of rear-end crashes at signalized intersections. Accident Analysis and Prevention 38(6), 1137-1150.

World Health Organization, 2015. Global status report on road safety 2015. World Health Organization

Yan, X., Radwan, E., Abdel-Aty, M., 2005. Characteristics of rear-end accidents at signalized intersections using multiple logistic regression model. Accident Analysis and Prevention 37(6), 983-995. 
Yasmin, S., Eluru, N., 2017. A Joint Econometric Framework for Modeling Crash Counts by Severity, Transportmetrica A: Transport Science, 1-26.

Yasmin, S., Eluru, N., 2013. Evaluating alternate discrete outcome frameworks for modeling crash injury severity. Accident Analysis and Prevention 59, 506-521.

Yasmin, S., Eluru, N., Lee, J., Abdel-Aty, M., 2016. Ordered fractional split approach for aggregate injury severity modeling. Transportation Research Record: Journal of the Transportation Research Board 2583, 119-126.

Ye, X., Pendyala, R.M., Washington, S.P., Konduri, K., Oh, J., 2009. A simultaneous equations model of crash frequency by collision type for rural intersections. Safety Science 47(3), $443-452$.

Zhou, M., Sisiopiku, V., 1997. Relationship between volume-to-capacity ratios and accident rates. Transportation Research Record: Journal of the Transportation Research Board $1581,47-52$. 